\title{
EXAMINING CONSIDERATIONS OF SOCIAL SUSTAINABILITY AND EQUITY WITHIN INTEGRATED COMMUNITY SUSTAINABILITY PLANS IN ONTARIO
}

\author{
By \\ Sabrina Güvenç \\ Bachelor of Arts (Honours), Ryerson University, 2017 \\ A thesis \\ presented to Ryerson University \\ in partial fulfillment of the \\ requirements for the degree of \\ Master of Applied Science \\ in the program of \\ Environmental Applied Science and Management
}

Toronto, Ontario, Canada, 2020

(C) Sabrina Güvenç, 2020 


\section{AUTHOR'S DECLARATION}

I hereby declare that I am the sole author of this thesis. This is a true copy of the thesis, including any required final revisions, as accepted by my examiners.

I authorize Ryerson University to lend this thesis to other institutions or individuals for the purpose of scholarly research

I further authorize Ryerson University to reproduce this thesis by photocopying or by other means, in total or in part, at the request of other institutions or individuals for the purpose of scholarly research.

I understand that my thesis may be made electronically available to the public. 


\title{
Examining Considerations of Social Sustainability and Equity Within Integrated Community Sustainability Plans in Ontario
}

\author{
Sabrina Güvenç \\ Master of Applied Science \\ Environmental Applied Science and Management \\ Ryerson University, 2020
}

\begin{abstract}
The concepts of sustainability, and sustainability planning, have become prominent in the last thirty years. In 2005, the Canadian government created a budget plan that was intended to fund infrastructure projects in municipalities across the country, as well as catalyze and strengthen sustainability planning within municipalities across the nation. In order for municipalities to receive the funding they needed to create Integrated Community Sustainability Plans (ICSPs) or provincial variants (ex. strategic sustainability plans). This thesis comparatively analyzes select integrated community sustainability plans in the Province of Ontario, Canada with specific focus placed on how and whether ICSPs address, define and advance social equity goals and principles in sustainability planning. Two questions drive the research: 1) How have ICSPs considered equity principles in their design and implementation; and, 2) How does variation in the degree of community involvement in sustainability planning influence how equity is addressed? This study draws upon qualitative methods including a comparative document analysis of ICSPs in Ontario and semi-structured key informant interviews. The overall findings suggested that equity was not strongly considered in the ICSPs analysed. There were few key results that emphasised this. Firstly there was a disconnect between policy goals and details within implementation strategies. There was found to be a lack of prioritization of equity, particularly with meaningful consideration of distributional equity. Lastly a lack of prescriptive guidance by the federal government and FCM with respect to goals and implementation.
\end{abstract}




\section{ACKNOWLEDGEMENTS}

This project could not have been done without the countless support and labour of so many people in my life. If I were to name every single person who has helped me through this process, even unknowingly, the list would be too long. Just know that every interaction I have had these past couple years has supported and motivated me throughout this project and my graduate studies at large. The following individuals named or mentioned deserve explicit praise for their contributions.

Firstly, I would like to express my greatest appreciation for my two supervisors, Dr. Sara Edge and Dr. Chris Gore, for their valuable and endless guidance, feedback and encouragement. They created a space in which I was able to grow, both academically and personally, throughout my graduate studies and I will be forever grateful for their mentorship. I would also like to thank my committee members, Dr. Pamela Robinson and Dr. Andrew Millward, for taking time to serve on my committee and provide valuable suggestions, questions and commentary.

Additionally, I want to thank the various union members, administrative staff and custodial staff at Ryerson University. They gave me the ability to complete this degree by providing me with the space and resources I needed throughout. It is their tireless work that gave me the space to learn and flourish, without their efforts I would not have been able to navigate my graduate studies. As well, this project would not have been possible without the interview participants from various municipalities across Ontario, their valuable insight helped shape this research.

I would like to give a very special thank you to my friends and family who have unconditionally loved and supported me throughout this project. To my colleagues and friends in the program, it was your companionship and excellence that motivated me every day. My friends (and extraordinary Toronto roommate) from both my homes in Ottawa and Toronto, the conversations, laughs, and tears shared these past couple of years have shaped me completely, it is your love and belief in me that is intertwined in every page of this project.

My family and partner have shown me endless care, love, guidance, support and joy throughout this whole project. They believed in me and my work on days that I didn't have the strength to do it myself. I cannot thank my partner enough for all he has done in supporting me and my graduate journey. Lastly, my parents and my brother are the truest inspiration and motivation behind this project, it is the three of them in whom I have modeled myself after, who taught me to ask questions endlessly, to always be critical of the answers, and the utmost importance of education. Thank you. 


\section{Table of Contents}

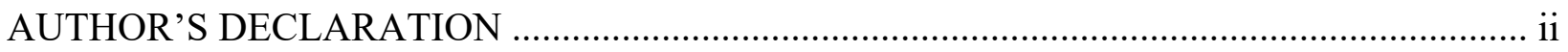

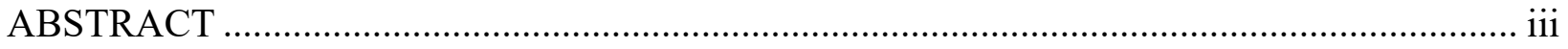

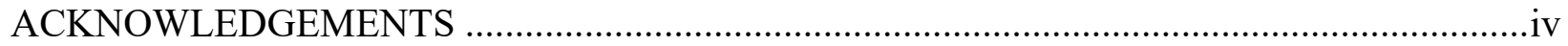

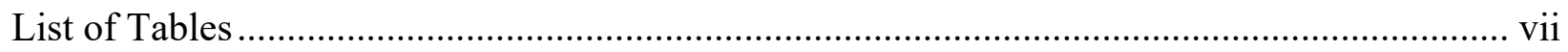

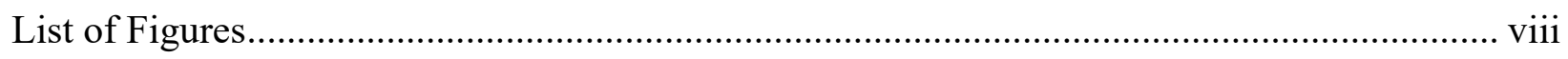

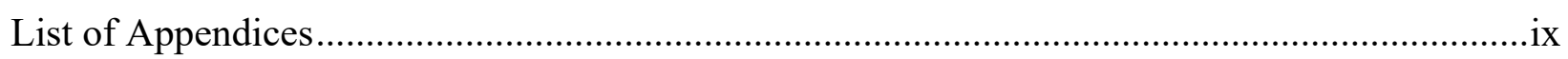

CHAPTER 1: INTRODUCTION \& STUDY RATIONALE .....................................................

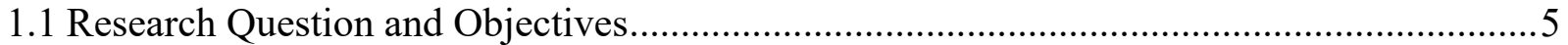

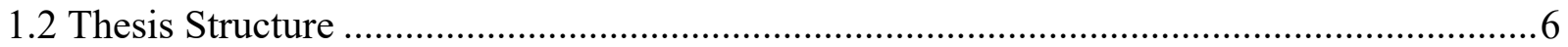

CHAPTER 2: REVIEW OF BACKGROUND LITERATURE ...........................................

2.1 The Implementation of Integrated Community Sustainability Plans in Canada ....................

2.1.2 Broader Research on Integrated Community Sustainability Planning ………………………………......12

2.2 Environmental Justice \& Equity in Sustainability Planning.................................................15

2. 3. Government vs. Community led Sustainability Planning .................................................18

2.3.1 Community Led (Bottom up) Governance ……………………………………………………………....19

2.3.2 Government Led (Top Down) Governance .....................................................................................22

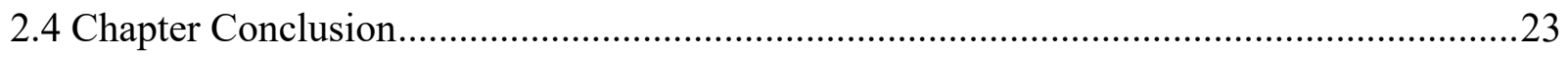

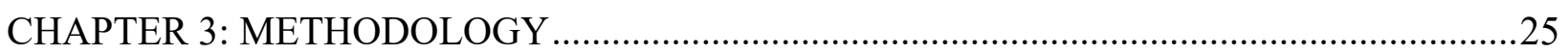

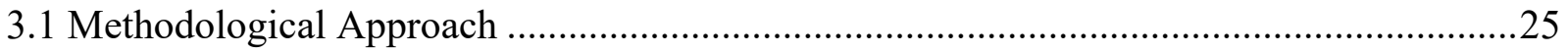

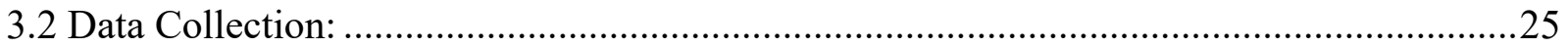

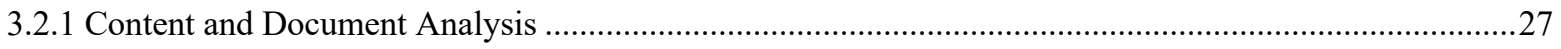

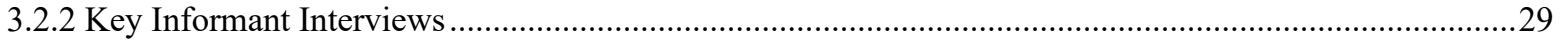

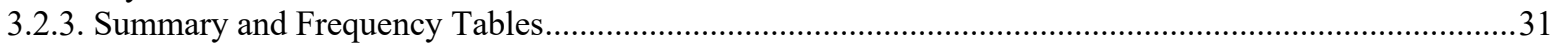

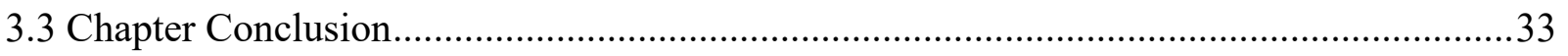

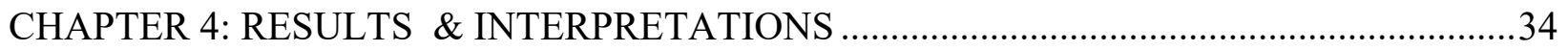

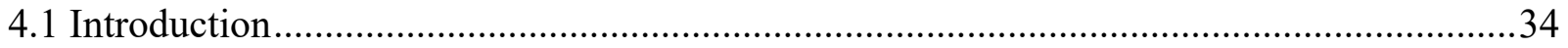

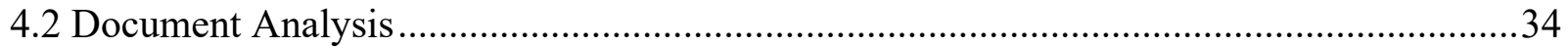

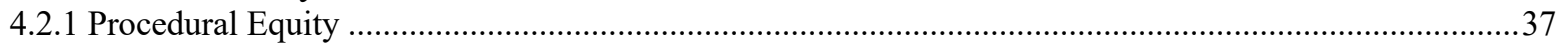

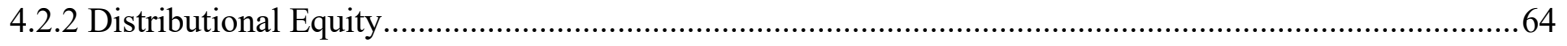

4.3 Broader Insights on the Governance \& Conceptualizations of ICSPs.................................86

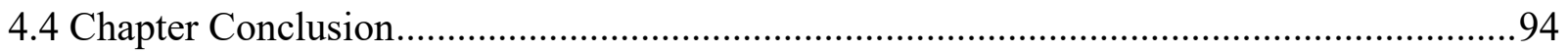

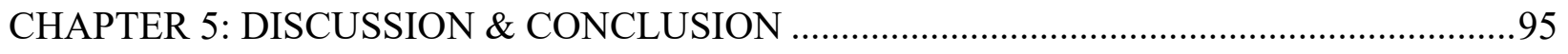

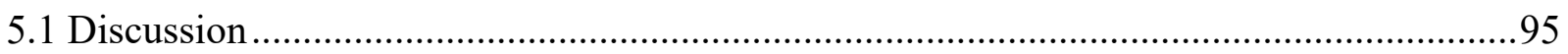

5.1.1 Disconnect Between Policy Goals and Implementation Details ...........................................................96

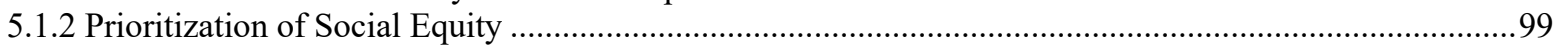


5.1.3 Lower Rankings for Distributional Equity

5.1.4 Lack of Monitoring and Prescription from Government ......................................................

5.1.5 Hard infrastructure vs. soft infrastructure (Social Dimensions of Sustainability).....................................108

5.2 Limitations of Study \& Recommendations for Future Research.................................. 110

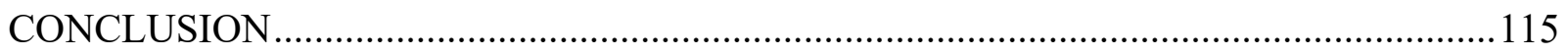

Appendix A: Sample Questions of Semi Structured Interview Guide ................................ 119

Appendix B: Table of All Interview Participants ............................................................. 121

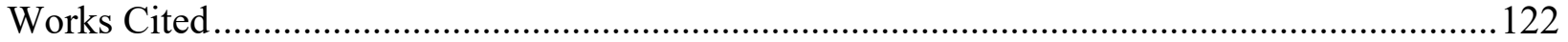




\section{List of Tables}

Table 1 list of Ontario ICSPs Analysed .................................................................................27

Table 2 Strength and Presence of Procedural Equity Codes in SPs ........................................35

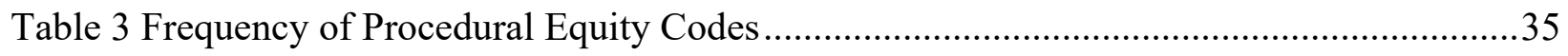

Table 4 Strength and Presence of Distributional Equity Codes in SPs ....................................36

Table 5 Frequency Table for Distributional Equity Codes .....................................................36

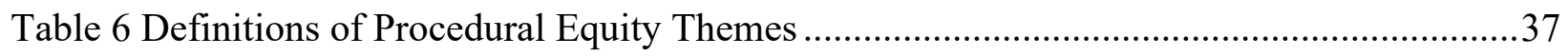

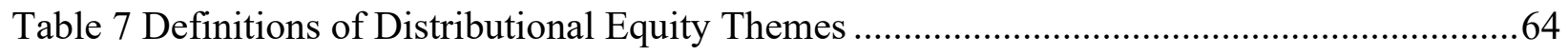

Table 8 Markham Ethnic Origin Census Data ................................................................. 112

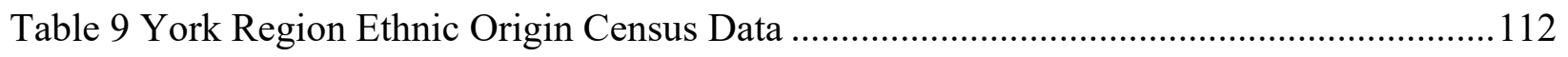

Table 10 Greater Sudbury Ethnic Origin Census Data ....................................................... 113

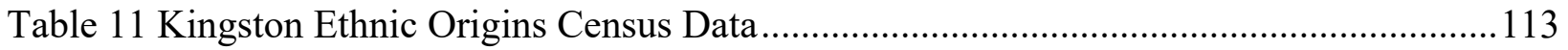

Table 12 Ajax Ethnic Origins Census Data...................................................................... 114

Table 13 Frontenac County Ethnic Origin Census Data ..................................................... 114 


\section{List of Figures}

Figure 1 Chart Providing examples of other types of plans that support ICSP principles. AMO (2007)

Figure 2 Example of Ajax's Arts and Culture potential action table Adapted from Ajax ICSP (2012) 43

Figure 3 Picture of Frontenac County Act on Recommendations of Frontenac Transportation Collaborative. Frontenac ICSP (2009) 


\section{List of Appendices}

Appendix A: Sample Questions of Semi Structured Interview Guide....................pg. 119

Appendix B: Appendix B: Table of All Interview Participants.........................pg. 121 


\section{CHAPTER 1: INTRODUCTION \& STUDY RATIONALE}

Sustainability in its most basic form can be defined as an idealistic framework aimed at maintaining the earth's carrying capacity through the changing of human behavior, and broader sociopolitical systems (Portney, 2003). As a concept, sustainability is very complex and nuanced with many different definitions and understandings. Sustainability's popularity and a more concrete definition arose in 1987, with the publication of Our Common Future, written by the World Commission of Environment and Development (WCED), (commonly known as The Brundtland Report). The Brundtland Report ambiguously defined sustainable development as "meeting the needs of the present without compromising the ability of future generations to meet their own needs," (WCED, 1987, pg. 43). The report identified three pillars of sustainable development including: economic, environmental, and social, arguing that sustainability cannot be achieved unless all three pillars are being addressed (WCED, 1987). Since this Commission there has been an emphasis on governing bodies integrating sustainable development, a subset of sustainability, into their policy frameworks and systems (Jordan, 2007). Sustainable development, and sustainability share the same foundational concepts, however sustainable development differs from sustainability in that it is focused more explicitly on economic activity and development (Portney, 2003).

Jordan (2007) explains that the root of sustainability being put forward as a key societal and governance priority, is in response to the need for enabling economic growth in the South to alleviate chronic poverty in ways that are sustainable over the long term, while also improving upon the efficiency and footprint of growth in the North to addresses mounting social and environmental concerns. Jordan goes on to argue that sustainable development was supposed to 
be seen as the answer to the "environment versus growth dichotomy" (pg.20) that has occupied discussions in both academic and public circles.

A major challenge that the concepts of sustainability and sustainable development face, is the absence of a universally accepted definition or details about how to move from principle to application (Portney, 2003; Owens \& Legree, 2015). This has left a number of academics and governing bodies uncertain about how to actually implement the concepts in practice, while also being free to apply it within and across unique socio-political, economic and environmental contexts. The ambiguity of the definition leaves gaps and confusion for governing bodies that have a desire to implement sustainability into their planning and policy practices (Portney 2003). Nevertheless, many governing bodies at various scales of jurisdiction are striving to strengthen prospects towards a more sustainable future through the implementation of sustainability ideals and principles in planning practices (Roseland, 2012). Sustainability is commonly pursued at multiple levels and jurisdictions of governance (e.g. local, provincial, national, international) (Markvart, 2015).

Sustainability planning at the municipal level was first introduced in Local Agenda 21 (Portney, 2003). These were mostly strategic plans focused on lowering greenhouse gas emissions, yet over time they started to evolve into a more holistic understanding of sustainability that also considered social, and economic pillars in addition to environmental, along with the importance of community participation (Chapple, 2015).

A range of government-driven and community or citizen led governance approaches have been drawn upon in an attempt to advance sustainability (Roseland, 2012; Robinson \& Dale, 2012). Governance, like sustainability, does not have a firm definition, however, Jordan (2007) explains it as "the patterns that emerge from governing activities of social, political and 
administrative actors" (pg.21). Governance is the structure of rules, norms and actions that include problem solving from various actors and stakeholders for a specific purpose. Governance encompasses a variety of institutional actors and stakeholders who all play important roles in governing a society.

Robinson and Dale (2012) analyzed the historic evolution of sustainable development and governance within Canada. In their research, they identified two important periods of time that can be categorized by different governance methods and approaches to implementing sustainability. The first period was between 1985-1995 which witnessed the start of sustainable development projects and "outcome driven approaches" or in other words emphasis on project outputs as opposed to the processes and approaches through which they were achieved (Robison and Dale, 2012). This period was also characterized by predominantly government led governance (as opposed to the private sector or civil society), in addition to a reliance on measurable and technologically driven programs such as energy efficiency projects, green buildings, green space, storm water retention ponds, etc. The second important period of sustainability planning and governance identified by Robison and Dale (2012) ranged from 2005-2009. They characterize this period as being marked by a new socio-economic system thinking approach and the need to develop new processes for engaging the public in sustainability decision-making through collaborative, and participatory processes (Robinson \& Dale, 2012; Berkes \& Folke, 1998). While the first wave touched upon the three pillars of sustainability (i.e. environment, economic, and social), the second wave places greater emphasis on the importance of more social dimensions of sustainability such as inclusive governance. Specifically, the second wave involved more emphasis on integrating the perspectives and needs of a broader variety of community actors and government stakeholders (Robinson and Dale, 
2012). In Canada, one example of a concerted effort to advance sustainability through a more integrated and inclusive approach was the introduction of Integrated Community Sustainability Plans (ICSPs) in 2005. ICSPs were a federally funded initiative to motivate municipalities across the nation to develop sustainability plans (Markvart, 2015). Since this time, approximately 239 ICSPs (and provincial variants of strategic sustainability plans) have been created in Canada (UAlberta, 2018).

Few studies have examined the impact and legacy of ICSPs in Canada (Markvart, 2015; Collins et al., 2017), or how key components within the plans are operationalized, defined or implemented. Previous research on sustainability plans in general has indicated that the social sustainability pillar has received relatively little attention in comparison to environmental and economic dimensions (Warner, 2002; Portney, 2003; Schrock et al., 2015; Markvart, 2015). ICSPs were intended to adopt a more holistic and integrated approach to sustainability that encompasses all pillars including social and cultural dimensions (Prime Minister's External Advisory Committee on Cities and Communities, 2005). Yet little research has examined the degree to which these dimensions has been taken up within ICSPs, or how whether social equity specifically is explicitly addressed within these plans. Within the context of climate action and sustainability planning, Schrock et al (2015) argue there is a need for prioritizing a focus on equity given "there is considerable evidence suggesting that the poorest and most vulnerable members of society will disproportionately bear the negative impacts of global climate change as it accelerates" (pg.282). They further suggest that sustainability plans that are sensitive to equity concerns may serve as tools for promoting "social and racial justice by tackling longstanding disparities and inequities within cities from food deserts to health disparities to unemployment and poverty rates" (pg. 282). Others argue sustainability planning cannot be achieved without 
full participation and engagement of community members (Warner, 2002; Portney, 2003) and how it is important to understand and acknowledge who is participating, who is excluded or disengaged, and who will ultimately benefit from sustainability plans as a result (Pearsall \& Pierce, 2010).

\subsection{Research Question and Objectives}

This thesis involves a comparative analysis to examine the following questions:

1. How have Integrated Community Sustainability Plans in Ontario considered equity principles in their design and implementation; and

2. How do variations in the degree of community involvement in the creation and implementation of Integrated Community Sustainability Plans influence how equity is addressed or prioritized?

These questions will be answered by conducting a comparative content analysis of select ICSPs in Ontario complemented by insights derived through key informant interviews with individuals that were instrumental in the design or implementation of those plans. The overall findings of this research suggested that equity was not strongly considered throughout the six ICSP that were analyzed. Some of the key results that arose that reinforced this finding were an apparent disconnect between identified policy goals and details in implementation. There was a limited prioritization of equity, particularly in respects to distributional equity concerns. There found to be a lack of prescriptive guidance by the federal government and FCM with respect to goals and implementation of the ICSP. Lastly the funding goals for the gas tax program may have inadvertently contributed to the lack of prioritization put on social sustainability and equity concerns. All these results and findings will be discussed throughout this thesis. 


\subsection{Thesis Structure}

The following chapter, (Chapter 2), gives context to the research being done within this thesis. It is a literature review that is broken down into three parts. These include a summary of existing literature on the ICSP program in Canada; a synthesis of the concept of environmental justice and equity and what this means in the context of sustainability planning; and a summary of key governance models that have been used in sustainability planning. Concepts of equity derived from environmental justice, namely distributional and procedural equity, will be used as the theoretical framework of analysis for this research. Chapter 3 presents the research methodology, outlining the parameters and justification for which ICSPs are being analysed, the qualitative document analysis that was done through a coding scheme and the semi-structured interviews. Following this, Chapter 4 describes and summarizes the results collected from document analysis and the semi-structured interviews. The document analysis results are separated into two different sections, that follow the two over-arching coding themes produced by the concepts from environmental justice, procedural and distributional equity. Then further interview data is summarized, and lastly a section on the different governance models within the 6 ICSPs are discussed. Finally, the last chapter, Chapter 5, is a discussion and conclusion of the research, giving an answer to the initial research questions and further discussing the results that were analysed, as well going over limitations and recommendations for future research. 


\section{CHAPTER 2: REVIEW OF BACKGROUND LITERATURE}

\subsection{The Implementation of Integrated Community Sustainability Plans in Canada}

In 2005, the Liberal Prime Minister, Paul Martin, and his government introduced a new federal budget entitled the New Deal for Cities and Communities (Prime Minister's External Advisory on Cities and Communities, 2005). This budget plan aimed to help municipalities cope with their enormous infrastructure needs, related deficits, and expanding jurisdictional responsibilities associated with provincial downloading. The objective was to create consistent funding for environmentally sustainable infrastructure that would help municipalities contribute towards the goals of cleaner air, water and the reduction of greenhouse gases (Bradford, 2007; Infrastructure Canada, 2008; Markvart, 2015; Office of the Auditor General of Canada, 2016). Within this specific budget plan it was stated that Canada's cities would receive a share of federal gas tax revenues worth $\$ 600$ million, and that the funding would increase until it reached $\$ 2$ billion dollars by 2009-2010 (later extended to 2015) (Markvart, 2015; Collins et al., 2017; Office of the Auditor General, 2016; Infrastructure Canada, 2008).

The criteria that was imposed for municipalities to receive Gas Tax funding was the development of an Integrated Community Sustainability Plan (ICSP) (Brandford, 2006; Markvart, 2015; Collins et al. 2017; Infrastructure Canada, 2006; Infrastructure Canada, 2008). This new budget plan was intended to provide resources for complex multi-faceted urban development problems, providing an innovative way for the federal government to play a more active role in shaping and supporting urban development policy (Bradford, 2007).

Gas Tax Funding has since become a permanent funding source for municipalities to help with infrastructure deficits, however the scope of this thesis will be limited to looking at the 
budget plan in 2005-2010 that required the creation of the Integrated Community Sustainability Plans (ICSPs) in order for municipalities to receive these funds. In other words, this thesis will not be looking at current uses of federal gas tax funds.

The portion of money each province and thus municipality received was calculated on a per capita basis with the intent of incentivizing all local governments into creating Integrated Community Sustainability Plans (ICSPs) to help Canada transform into a more sustainable country (Infrastructure Canada, 2006; Infrastructure Canada, 2008; Office of the Auditor General of Canada, 2016). ICSPs were supposed to emphasize long-term thinking, collaboration between departments and sectors, engage community stakeholders, create partnerships, and ensure continuous monitoring and evaluation (The Natural Step, 2018). The ICSPs were not required to be created solely in house by each municipality, meaning that municipalities could hire private consultants to help them in creating the sustainability plans. The Green Municipal Fund created by the Federation of Canadian Municipalities to help fund the ICSP program stated that some of their funding money could go towards consultants for the creation of the plans (The Office of the Auditor General, 2016). Thus, the authors of some plans are third-party consultant groups. This thesis does not investigate the potential role that authorship may have played in determining the details of the plans.

The criteria for what constituted an Integrated Community Sustainability Plan was interpreted quite broadly (Prime Minister's External Advisory on Cities and Communities, 2005; Infrastructure Canada, 2006; Markvart, 2015). Only general requirements of what needed to be included within the ICSPs were provided. These included the fact that the plans had to be long term, integrate all four sustainability pillars (social, cultural, environmental, and economic), and involve the participation of community members (Prime Minister's External Advisory on Cities 
and Communities, 2005; Infrastructure Canada, 2006; Infrastructure Canada, 2008). The

Government of Canada requested consideration of an additional sustainability pillar (i.e. cultural) based on the rationale that "cultural investments can reinforce place-based community development objectives related to employment and innovation, neighborhood revitalization and environmental sustainability" (Prime Minister's External Advisory on Cities and Communities, 2005).

The Association of Municipalities of Ontario's (AMO) ICSP background document (2007) gave a four-point outline of principles that needed to be demonstrated within the ICSPs to meet the requirements of eligibility of funding:

1. a co-ordinated approach to community sustainability (e.g., linkages of various plans, planning and financial tools that contribute to sustainability objectives);

2. evidence of integrated social, cultural, environmental and economic sustainability objectives in community planning;

3. collaboration with other Municipalities where appropriate to achieve sustainability objectives; and;

4. engagement with residents in determining a long-term vision for the Municipality

These principles were echoed in a number of federal and provincial documents (Prime Ministers External Committee on Cities and Communities, 2005; Infrastructure Canada, 2006; Office of the Auditor General of Canada, 2016).

Given requirements were quite general, there were a variety of different types of planning documents that were considered acceptable as ICSPs or suitable equivalents, including Strategic Sustainability Plans, Sustainability Plans, and Municipal Sustainability Plans. The AMO (2007) backgrounder document clarifies that Official Plans, as well as other variants can also demonstrate the principles or spirit of an ICSP, and therefore be contenders for the Gas Tax 
Funding. The AMO created a graphic (see Figure 1.0) to visually demonstrate examples of other types of plans that are "supportive of ICSP" principles.

Figure 1 Chart Providing examples of other types of plans that support ICSP principles. AMO (2007)

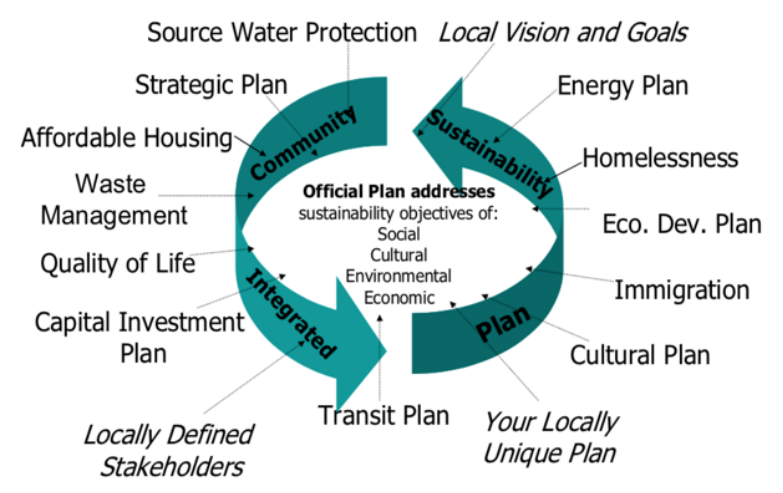

The AMO document (2007) also gave municipalities and regions two suggested steps to meet ICSP requirements. The two steps are loosely defined, they state that municipalities/ regions, should take stock of all existing plans and describe how the community will be achieving sustainability, and secondly, they should find opportunities for connections to be made between capital investment and sustainability for each community. This short document did not provide many specific prescriptions for municipalities and regions to follow.

Over time, a number of government bodies including the federal government, different provincial governments, municipal governments, and the Federation of Canadian Municipalities published documents related to ICSPs. These included documents that provide a general summary of the ICSP program, and some research reports that provided findings on sustainability planning initiatives and/or the ICSP process.

There are limited government affiliated documents dedicated to providing background information on the Integrated Community Sustainability Plan program (e.g. AMO, 2007; Prime 
Minster External Advisory, 2005). The few that exist intend to provide stakeholders with a better understanding of the key barriers to developing and implementing ICSPs, provide guiding principles for ICSPs, and guidance on the development and implementation of ICSPs (Prime Minister External Advisory, 2005). Other third-party companies have also attempted to create background documents about the ICSP and Gas Tax Fund program. For instance, The Natural Step, a non-profit consultation company, has created background and implementation resources for municipalities/regions looking to create an ICSP.

With respect to guidance around the creation and implementation of ICSPs, The Prime Minister's External Advisory on Cities and Communities (2005), emphasizes 11 key principles. The ones of particular relevance for this thesis are 'Considerations of Equity', and 'Public Involvement'. The government suggested that equity impacts should be considered in decisionmaking, including both indirect and long-term equity implications that may be imposed on future generations (pg.20). With respect to public involvement, the document asserted that successful implementation of sustainability cannot be achieved without the support, feedback and ongoing community input (pg. 20). This document also acknowledged the importance of equity and public engagement within ICSPs, which makes it stands out from most other background information, for this is the only guiding document that explicitly addressed these principles.

Within the Natural Step and Infrastructure Canada (2011) they explored the current state of sustainability planning and the success factors and barriers of ICSPs. One success factor that they looked at was whether municipalities were being transparent and accountable with specific focus on examining whether municipalities were providing feedback to community members on their plan and progress (pg.18). Their survey found that $77 \%$ of their respondents acknowledged the essential importance of effective community engagement within sustainability planning 
which includes appropriate feedback mechanisms. This thesis will also examine communication and feedback strategies, yet greater emphasis will be placed on whether and how the public is able to provide feedback, and whether planning and decision-making processes are procedurally just. Unlike the Natural Step and Infrastructure Canada (2011) report in which they only asked the respondents what they found to be successes.

\subsubsection{Broader Research on Integrated Community Sustainability Planning}

There are a limited number of academic papers looking into ICSPs in Canada, yet there are a few key scholars that have examined their legacy (Markvart, 2015; Collins et al., 2017). Further, very little attention has been devoted to looking into the integration and implementation of the social sustainability pillar, and specifically social equity concerns within Integrated Community Sustainability Plans, particularly within the context of the Province of Ontario. There are a few exceptions. For example, Duxbury and Jeanotte (2012) examined how the cultural pillar is considered within ICSPs in Canada, (Infrastructure Canada, 2006). For their study, they examined 17 guides to creating ICSPs that municipalities would have used, as well as ICSPs themselves to examine how culture was being integrated into the plans (Duxbury, Jeanotte 2012). Their findings were quite bleak for they found that even though there was some consideration of culture within ICSPs which suggests a growing awareness of the connection between culture and sustainability, true integration of cultural considerations within sustainability plans remained very limited within the ICSPs that they looked at (pg.130). They found that ICSP action items favoured environmental infrastructure investments and economic development strategies: 
concrete actions seem disconnected from holistic definitions of sustainability or cultural sustainability, the action plans do not prioritize cultural items, and culture-related items within economic and social sustainability contexts appear to be "minor" suggestions (pg. 14).

These findings are consistent with another study done by Grant et al., (2016), which focused on ICSPs in Atlantic Canada. It concluded that the plans lacked any sort of direct contribution to social or cultural sustainability. These studies support the need to explore these issues within Ontario's context.

In Markvart's (2015) study, she found that there is a disconnect between the ICSP goals outlined at the federal level and the actual process of implementing the ICSPs locally, suggesting implementation gaps are common in municipalities across Canada. An issue that may explain this disconnect is the fact that prescriptive criteria imposed by the federal government was very general, resulting in very broad flexibility in the design of these plans at the local implementation level, and a lack of one consistent template or framework (Markvart, 2015; Ling et al 2009). Others similarly argued that the degree of flexibility may have served as a barrier to consistent or effective implementation (Marbeck Resource Consultant, 2009; Infrastructure Canada and The Natural Step, 2011). On one hand breadth and flexibility is helpful in that municipalities have the ability to customize their plans to fit their own needs; however, it may also reduce the level of accountability expected from municipalities in achieving meaningful integrated sustainability policy (Marbeck Resource Consultants, 2009; Ling et al., 2009). Furthermore, it has been suggested that this ambiguity has the potential to undermine emphases on equity and social dimensions of sustainability in particular because without specific criteria that compels municipalities to focus more narrowly on green physical infrastructure (Bradford, 2007). For example, in their evaluation of ICSPs in Atlantic Canada, Grant et al (2016), noted that, 
"proposed projects rarely promised direct contribution to social or cultural sustainability" even though that is one of the only criteria for the plans laid out by the government of Canada.

This critique of ICSPs is also echoed by Bradford (2007), who analyzed the entire New Deal for Cities and Communities policy. He highlighted the problematic relationship between requiring social and cultural sustainability dimensions to be considered, despite the fact that the policy aimed to focus more narrowly on providing funding for hard infrastructure projects. Bradford went as far as stating that the gas tax fund revenue transfers are not the tool to address growing poverty and social exclusion due to the inherent focus on hard infrastructure (2006). In line with conclusions drawn by Duxbury \& Jeannotte (2012), Markvart (2015), and Grant (2016) that social dimensions and equity are not addressed within ICSPs, Bradford stated that he did not believe the "government had thought through implementation of anything beyond the economic and environmental dimensions" (Pg.19). These critiques are further supported by Infrastructure Canada and The Natural Step (2011) which reported that public infrastructure is a central theme in sustainability planning, particularly "decisions around the development, operation, maintenance and renewal of buildings, roads, paths, parks, water, energy, and other infrastructure [which in turn] have significant implications for community development and quality of life"( 2011, pg.7). This kind of emphasis can result in disproportionate concentration on hard infrastructure changes, as opposed to soft infrastructure, like public health, recreation, children and family services (Bradford, 2007). These critiques further justify the need for exploring how social sustainability and equity is considered within the design and implementation of Ontario's ICSPs specifically. 


\subsection{Environmental Justice \& Equity in Sustainability Planning}

One framework and school of thought that holds potential for informing attempts to analyze how sustainability plans address equity during their creation and implementation is environmental justice. In general, environmental justice is defined as the uneven burden or distribution of risks, harms or health supporting services, and inequitable socio-political participation within environmental governance (Minkler, 2008). This can be seen within sustainability planning when certain communities and groups of people benefit and have access to more sustainable infrastructure, as well as more opportunity and funding to participate in sustainable initiatives (Campbell, 2013). There is no one definition of environmental justice, however two prominent components of the theory are procedural equity and distributional equity. Procedural equity focuses on "the right of all people to participate in environmental decision making" whereas distributional equity focuses on how "environmental benefits and burdens [are] distributed across places and people" (Pearsall \& Pierce, 2010, pg.571).

When focus is only placed on distributional inequity this can result in only looking at how risks are unevenly distributed across space and place thereby disproportionately impacting certain populations (Teelucksingh \& Masuda, 2014). Teelucksingh and Masuda (2014) argue that:

distributional explanations of injustice [...] not only ignore power relations, but risk reinforcing hegemonic structural inequalities by allowing forms of discrimination and privilege to remain hidden and unquestioned. This can be avoided by considering politics of space, which can explain why certain marginalized groups and communities continue to be vulnerable to environmental injustices (p.303).

These authors argue for the need to better understand who dictates which individuals and communities benefit from sustainability measures, and how this unfolds through particular processes. Thus, the concept of environmental justice that Teelucksingh and Masuda (2014), 
Pearsall and Pierce (2010),) embrace emphasizes both procedural equity in decision-making in addition to distributional equity. This thesis will consider both of these factors, when analyzing ICSPs by using these two themes as the thematic framework for the document analysis.

Previous studies have looked at how sustainability planning addresses environmental justice, specifically within the United States. Three influential studies conclude that within sustainability planning initiatives and indicators there is a huge gap in social sustainability, equity and environmental justice (Warner, 2002; Portney, 2003; Pearsall \& Pierce, 2010).

These previous studies support the utility of using environmental justice theory as a framework for analyzing ICSPs. They point towards the concept's comprehensiveness in being able to asses and analyze many different social dimensions of sustainability (e.g. inclusive governance and decision-making), and related access to or interaction with various forms of sustainable infrastructure (e.g. transit, greenspace, etc.). Warner's study (2002) examined 33 cities with a population of 200,000 or more that had published their sustainability plans or indicator projects on the internet. Specifically, he explored whether environmental justice had been considered within conceptual/educational materials, policy objectives, and implementation content. Of the 33 cities examined, only seven were found to have engaged with the term environmental justice within their planning and indicator documents (Warner, 2002). Only one city, San Francisco, engaged with the concept explicitly within the context of implementation strategies (Warner, 2002).

Pearsall and Pierce (2010) redid Warner's (2002) study to determine what if anything had changed, nine years later. Their analysis was also split into three different levels: conceptual/educational materials, policy objectives, and indicators. Pearsall and Pierce (2010) found that out of the 107 cities in the United States they studied, only 31 included environmental 
justice as a "conceptual component" (pg.573) of their sustainability plans and only 13 out of the 107 considered environmental justice within their indicator projects The findings from their analysis also demonstrated that among plans that do consider environmental justice, indicators that were used to try and track this kind of progress tended to focus on aggregate measurements of change, and not specific sub-populations based on geographic or demographic factors. This approach may inadequately capture inequities that remain within and between populations (Pearsall \& Pierce, 2010). They also found that there was an underrepresentation of indicators that monitored the processes through which decisions were actually being made (Pearsall \& Pierce, 2010).

Pearsall \& Pierce (2010) explain how aggregate measures of quality of life (that consider health, housing, safety, and other social sustainability dimensions) could be rising yet this does not inherently indicate that all communities are benefitting or gaining access to positive impacts equitably. Sustainability plans could be measuring social indicators related to quality of life or well-being, and while these may increase within the city as an aggregate whole, individual communities could be bearing the burden of negative measurements that get ignored in the aggregate. They argue the measurement of quality of life fails to acknowledge both the procedural and distributional elements that are essential to environmental justice and equity. Therefore, there remains need for works that consider the degree to which aggregate measurements of environmental justice versus community and geographical measurements within the content and creation of ICSPs.

The concepts of quality of life, social equity, and community engagement are intrinsically connected and important to social sustainability, yet understanding their differences is imperative. As explained by Pearsall \& Pierce (2010), many sustainability plans do address 
social sustainability dimensions and rely heavily upon community engagement and participation within their sustainability planning (Markvart, 2015). However, this does not inherently mean social equity is addressed given there can be high levels of community engagement and participation, yet inequitable representation in regards to who is actually participating and who is excluded. Attention to social equity must be upheld within processes of community engagement because 'community engagement' does not really mean much unless you are critically examining who is engaging and who has equal opportunity to do so (Pearsall \& Pierce, 2010). Similarly, social sustainability dimensions look at quality of life indicators but that does not inherently mean it critically engages with equity if improvements to quality of life are not equitably distributed across society and space.

\section{3. Government vs. Community led Sustainability Planning}

Sustainability planning can be adopted through different governance models and approaches that can yield different outcomes such as varying levels of citizen engagement, partnership engagement, cross sectoral planning, opportunities and funding (Collins et al., 2017). Since the 1980s there has been a social ideological shift in North America towards free market neoliberalism (Coburn, 2004). This paradigm shift emphasizes market-based decisions and policies and decreases in government investment in social programs and institutions (Coburn, 2004). McClintock (2014) defines the outcomes of neoliberalism as a "rolling back' of the safety

net and government oversight, and the 'rolling out' of new social and economic relationships that further fuel capitalist accumulation" (pg.154). This shift has had profound implications for the ways in which the environment is managed, including the implementation of sustainability planning initiatives (Portney, 2003, p.4). 
A study done by Collins et al (2017) examined the implementation of ICSPs in three midsize Ontario cites including Kingston, Burlington and Markham. They specifically looked at the different governance models used in each of these cities and how that affected the sustainability planning implementation strategies (Collins et al., 2017). The governance models that were examined in this study were categorized as community-led governance and government-led governance (Collins et al., 2017). They give a loose definition of these models stating that topdown is a "city-owned approach", bottom -up is a "community owned approach which the city is one partner" (Collins et al., 2017). The findings from Collins et al (2017) study shows that each governance model has strengths and weaknesses for sustainability planning. For example, they found that partnership building and community engagement within sustainability plans (and ICSPs in particular) was stronger within community-led governance models, whereas government-led governance models were particularly important and more effective in larger and more dynamic cities where sustainability action must take place across the large complex systems (Collins et al., 2017). While Collins et al., (2017) focused on the impact of governance models on sustainability planning and implementation approaches in general across Ontario, this current study focuses more specifically on the impact of different governance models on the ways in which equity is considered (or not) within sustainability planning in Ontario, and whether some governance approaches appear to more effective than others.

\subsubsection{Community Led (Bottom up) Governance}

Robinson \& Dale (2012) describe Community-led Governance as a governing model where initiatives and policies start at the community level and have the ability work their way upwards through government structures. It is also referred to as bottom up governing (Robinson Dale 
2012). This governance model goes beyond community participation and it strives for the community having control and authority over processes of decision-making. It can be hard to draw a firm line between community-led and government-led governance models because in reality power dynamics shift over time and initiatives in practice may involve elements of both. Yet overall, community-led approaches place emphasis on empowering communities, giving them clear authority to influence initiatives and outcomes. Whereas in government-led the process is controlled by, and authority is held by government authorities.

Community-led governance models have become popularized since neoliberalism has become the entrenched socio-economic system, which led to social policies shifting away from the welfare state. In its place, there has been a downloading of responsibility for programing, infrastructure development and services to the individual through privatization and commercialization (Coburn, 2004; Wolch, 2014; McClintock, 2014; Heynen, 2006). This has included a decrease in government monitoring of environmental issues, a greater reliance on the market to solve environmental problems, and a greater burden on communities to take a lead in responding to environmental concerns (Coburn, 2004; Wolch, 2014 \& McClintock, 2014; Heynen, 2006). Coburn (2004) and Heynan et al., (2006) have argued that neoliberalism and increasing privatization of urban environmental management creates a large inequality gap in access to resources between the upper and lower classes, and simultaneously undermines the social institutions which might help reduce inequalities. For example, Wolch et al., (2014), argue that neoliberalist policies lead to inequitable distribution in access to greenspace and related benefits to mental and physical health. This occurs because putting the onus on communities to create their own greening and/or sustainability programs leads to some communities being less able to engage in the planning process or garner the capacity required to secure green and/or 
sustainable infrastructure while other communities consisting of more privileged demographics comparatively prosper. Wolch et al., (2014) and McClintock (2014) similarly argue that top down/ government-led implementation of greening and/or sustainability initiatives, is also problematic from an equity perspective as it can lead to 'eco-gentrification' (i.e. consequent rising property values and displacement of vulnerable individuals as more affluent citizens desiring new green spaces move in). The solution proposed by Wolch et al., (2014) is that the implementation of new green space has to be led and organized by the community in partnership with municipal government actors, particularly city planners in order to identify, meet and then ultimately protect the needs of the community.

Many academics who discuss different governance models for sustainability planning insist on community participation and engagement as a way of achieving equitable policies (Head, 2007; Teelucksingh et al., 2014). However, historically, engagement within sustainability planning and environmental governance has been predominantly driven by "elite and middleclass segments of society" (Campbell, 2013, p. 84). Putting the onus on communities to create their own sustainability plans and projects can lead to inequitable distribution of sustainability infrastructure and related benefits, given not all communities have the ability to participate equally.

Heynan et al (2006) argue that one of the shortcomings of community-led governance is that it limits the prospects for promoting equity. They argue for the need for government-led governance within sustainability planning to collective redistribute resources on the part of the government, enabled through state taxation. 


\subsubsection{Government Led (Top Down) Governance}

Government-led governance can be categorized as top-down model of governing. This involves governments taking leadership roles in creating and implementing the infrastructure and policies that are needed to achieve sustainability. In Roseland's (2012) book he states that a "traditional government approach is top-down, hierarchical and operates in isolation from other stakeholders" (pg.262). This is a very classical and straight forward definition of top down, that involves more command and control policy tools that are government made. For this thesis, an expanded notion of top-down will be used to include a more holistic understanding of government-led governance that still involves community partnership. Under this approach, the fundamental principles of top down approaches are upheld, however, the importance of community participation and consultation in planning and action is also emphasized, which gives recognition that community sustainability planning cannot be accomplished without citizen participation (Portney, 2003; Pearsall \& Pierce, 2010). However, citizen participation does not intrinsically mean community led.

The discourse around the degrees of power afforded to citizens when operationalizing participation started with Sherry R. Arntstein (1969). Her work visualized the extent of citizen power in participatory planning as a ladder, where manipulation and tokenistic engagement of citizens rested at the lowest rungs, and as you climb up the ladder you move towards more delegated power and citizen control (Arnstien 1969 pg.217). The image of the ladder is to show how community participation is a spectrum, complex and a gradient. Planning policy or projects can use several different levels of community participation. For this thesis, the working criteria for categorizing something as community-led or government- led is looking at whether government or community organizations took the lead in creating and implementing the ICSPs 
or sustainability planning process. Specifically for ICSPs it has been mostly municipal governments that have taken the lead in the process of creating the sustainability plan in order to receive funding, however in some cases, like The City of Kingston, after the creation of the initial plan, responsibility and control for implementation and future decision-making was passed along to the community (Collins et al., 2017) If a sustainability plan is being created by community members but receives government funding and grants it is categorized as community-led plan. Conversely if a plan is government dominated yet still implements aspects of community participation then it will be categorized as government-led.

There is a marked contrast between Wolch's (2014) call for the removal of government intervention and emphasis on community driven initiatives, and Heynen et al's (2006) call for more state control and power in order to achieve greater equity. My thesis seeks to contribute to this discussion by considering which governance approaches are more likely to consider principles of equity and justice within the context of ICSPs in Ontario.

\subsection{Chapter Conclusion}

The purpose of this chapter was to provide a background and contextual framework of relevant literature for this study. Section 2.1 gives a critical account of the background understanding of the ICSP program and its shortcomings. Some of the emergent findings from the literature review are that there is a focus and encouragement of green infrastructure within the ICSP program, versus a more holistic approach to sustainability that encourages all three pillars (social, environmental and economic). As well, research complements this focus by highlighting the lack of social equity (and subsequently social sustainability) within the ICSPs created across Canada. 
Section 2.2 gives a contextual understanding to the environmental justice framework that is being used to analyze the data for this study. This section highlights the importance of integrating both procedural and distributional equity within the framework of environmental justice. In addition, this section outlines previous studies that have analyzed how sustainability plans address equity and environmental justice, further justifying such an approach for this project.

Section 2.3 gives background and context for two different governance methods that are being used in the analysis of this study. This section looked at both government-led, and communityled highlighting both their positive attributes and their shortcomings. These governance methods are being used in this study to see if there is any correlation between the different governance methods and addressing equity in the Ontario ICSPs being analyzed. 


\section{CHAPTER 3: METHODOLOGY}

\subsection{Methodological Approach}

This thesis uses qualitative methods which are ideal for exploratory studies and providing rich and detailed description of previously unexplored phenomena (Appleton, 1995).

\subsection{Data Collection:}

This thesis examines both the design and implementation strategies of ICSPs. These two areas are being studied using two data collection techniques: content analysis of ICSP documents and key informant interviews. The only time frame imposed on the data collection is that funding for the ICSP program began in 2005 thus there were no plans for analysis prior to that year (Ling et al., 2009; Markvart, 2015; Infrastructure Canada, 2008).

The Integrated Community Sustainability Plans (ICSP) that are being analyzed in this study have been collected from the Canadian Sustainability Plan Inventory that was compiled by the University of Alberta (UAlberta, 2018). The inventory database collected all public sustainability plans, which includes ICSP and "provincial variants" from across Canada (UAlberta, 2018). Provincial variants are any of the other acceptable forms of sustainability plans that can be considered ICSPs, like municipal official plans, strategic plans etc. On the website the inventory allows the user to search for plans according to a number of variables: date of plan creation, province, population, municipality, author, plan name (type) and whether the plan was created by a public organization, private organization, or formed by multiple parties.

For this study the search focused on all public plans from municipalities and regions within the province of Ontario that have a population 100,000 people or greater as of the year 2019. This population size was chosen because it supports Statistics Canada's definition of a 
Census Metropolitan Area (Stats Canada, 2015), which are more likely to have a sustainability plan than rural counterparts (UAlberta, 2018). In total there are 19 plans in the database that fit these criteria, the plan types are: official plans, ICSPs, strategic sustainability plans, and sustainability plans. From these 19 plans, six sustainability plans were chosen for analysis (including sustainability plans and strategic sustainability plans) from Ontario. These six plans were selected after excluding all municipalities that chose to modify their Official Plan to consider sustainability objectives (as opposed to creating a plan that was explicitly intended to focus on sustainability). See Table 1 for a list of all six Ontario ICSPs analysed within this study.

The Greater City of Sudbury's plan was included, despite the fact that it is not called an Integrated Community Sustainability Plan, however according to the Association of Municipalities of Ontario, it did receive Gas Tax Funding in 2005-2010 (AMO, 2007), and the plan was an equal variant to the ICSP and therefore eligible for funding (Infrastructure Canada, 2008; Markvart, 2015). It is worth noting that there are two other cities on the University of Alberta Inventory that have a population over 100,000. These include Kitchener and Barrie. These two plans were not included for analysis as Kitchener's community strategic plan does not focus on sustainability and Barrie's plan is not substantial enough to analyze, i.e. it is more of a pamphlet then a comprehensive planning document.

Frontenac County does not have a population of 100,000 , however it was nevertheless included for analysis as it was the only regional government in Ontario that had a stand-alone ICSP designated document. The other three regional jurisdictions in Ontario with ICSPs are York Region, North Durham and Lanark County. North Durham Region's ICSP does not cover its entire county, for the planning document only covers 3 out of 7 townships, as well Lanark County document is being used to create an Official Plan, thus not a stand-alone sustainability 
plan. The reasoning behind keeping Frontenac County's ICSP in the analysis in addition to York Region's Sustainability Strategy plan (the only other plan developed at the regional level being included in this analysis), was that York Region's ICSP does not follow the same format as the other ICSPs, in that is does not include a cultural pillar within its document. Yet a representative from the York Region Long Range Planning department confirmed that the plan was created for the ICSP program and Gas Tax Funding was received. It is helpful to include Frontenac County's ICSP in the analysis, because it fits the 'recommended' criteria of ICSPs and provides a regional government perspective in creating and implementing the ICSPs to complement a municipal governance perspective that is reflected in the other selected sites.

Table 1 list of Ontario ICSPS Analysed

\section{ICSPS ANALYSED}

THE CITY OF MARKHAM: MARKHAM GREENPRINT 2011

THE CITY OF KINGSTON: SUSTAINABLE KINGSTON 2010

THE GREATER CITY OF SUDBURY: EARTHCARE SUDBURY 2010

THE TOWN OF AJAX: A JOURNEY TO SUSTAINABILITY PLAN 2013

FRONTENAC COUNTY: DIRECTIONS OF OUR FUTURE- SUSTAINABILITY

PROJECT RECOMMENDATIONS 2009

YORK REGION: SUSTAINABILITY STRATEGY PLAN 2007

\subsubsection{Content and Document Analysis}

Qualitative document analysis was undertaken as part of this study to examine how and why certain documents were created, as well as understanding and analyzing the content within them (Coffey, 2014, pg. 270). The analytical strategy of thematic analysis has been used during this 
study to determine whether the selected Ontario ICSPs implement principles of social sustainability and equity. Open-coding was used to identify emergent themes that either confirm or deny the presence of equity principles in addition to examining how and whether the concept of equity is being defined or connected to specific implementation strategies. Thematic codes were created through a combined inductive and deductive approach (Gale et al., 2013). Open coding involves coding "a large volume of text so that segments about an identified topic (the codes) can be assembled in one place to complete the [analysis] process" (Crabtree \& Miller, 1999). With a deductive approach, codes are predetermined from insights derived from previous literature, whereas with an inductive approach codes and themes are created from data collected from the ground up through open coding (Gale et al., 2013). It is useful to use a combination of both approaches when the research has specific goals for the document analysis but also aims to explore other unexpected findings (Gale et al., 2013).

From a deductive approach the codebook used the overlying principles of environmental justice, procedural justice and distributional justice (Teelucksingh \& Masuda, 2014; Pearsall \& Pierce, 2010) as overarching themes, under which twenty-five sub codes were created. Under the code of procedural equity, examples of sub-codes that were created include: accessibility, public engagement, indicators monitoring community engagement. Under the overarching code of distributional equity, sub-codes included community focused projects/initiatives, marginalized induvial/community focused projects/initiative, indicator measurements based on aggregate, and indicator measurements based on community populations. Full definitions of each code are found in Table 5, and Table 6 .

The qualitative software NVivo (v12) was used for the coding of each plan and interview transcripts. NVivo is a software that allows researchers to code and assist with the organization 
and visualization of the information. Frequency of codes in each ICSP was counted and put in a table (Table 3 \& Table 5) using NVivo.

The codes from each ICSP were then analysed and ranked from a scale of 1-4, based on each plan's strength and presence of the theme, which is furthered explained in section " 3.2 .3 Summary and Frequency Tables". The ranking style is similar to one done in Schrock et al., (2015) study, in which they used a qualitative coding scheme to analyze how equity was addressed in climate change plans and ranked them on a scale of 0- 3 (pg. 286).

\subsubsection{Key Informant Interviews}

To further address the question of how ICSPs engaged with equity as well to give further supportive information on the role citizens and communities played within their production and implementation, key informant interviews were conducted. The interviews complemented and furthered the information discovered in the initial document analysis. Key informant interviews are particularly useful for providing researchers with an understanding of others' perspectives and specific knowledge that cannot be attained by the researcher on their own for it is "unavailable except for the key informant" (Crabtree \& Miller, 1999). The interviews allow indepth discussion with professionals and stakeholders who have worked on the creation and implementation of sustainability plans to get a further insight into how they address and engage with equity and social sustainability. Examples of questions that were posed to key informants include: How are certain areas and populations picked for specific sustainable infrastructure projects? How has the community participated within the creation and implementation of the plan? A more detailed summary of questions that were asked during the interviews can be found in Appendix (A). 
All municipalities and regions that were included in the content analysis were contacted in an attempt to recruit willing key informant interview participants. Unfortunately, after repeated attempts, I was not able to obtain a response from representatives from every municipality/region. In total 8 interviews were done. This included representatives from the municipalities/regions of Kingston (2), Markham (1), Sudbury (1), York Region (1), Frontenac County (1). A table of interview participants, their job title, the municipality/ region they work for and the date of the interview is in Appendix (B). Additional interviews were undertaken with a representative from the Federation of Canadian Municipalities and a consultant with expertise on ICSPs.

This study adopted a semi- structured interview style. Semi- structured interviews allow for versatility and flexibility in questioning while still being based on a structured theme and interview guide (Kallio et al., 2016). This is useful when interviewing different municipalities/regions as the questions can then be tailored to the unique initiatives and plans of each municipality while maintaining a general and consistent structure and purpose. These interviews were done over an online conference application called Zoom and took approximately one hour per interview. Having the interviews completed over a conference call eliminates any geographic barrier that could arise when selecting municipalities to interview. The conversations were recorded and transcribed in order to be analyzed through the same thematic analysis as done with the document analysis. In addition to the coding scheme that was utilized for the document analysis some additional codes emerged from the interview data through an inductive coding process. This study received approval from the Ryerson Ethics Board.

Given the focus on considerations of equity and social sustainability in plan design or implementation, one acknowledged limitation of this study is that the interviews are limited to 
professionals who were involved in the creation and/or administration of these plans, which does not include broader community members who directly experienced and interacted with the infrastructure changes or initiatives that may have come out of the plans. It should be acknowledged that interviewing as a method of research can be contentious for it could be prioritizing certain people and voices that come from privileged backgrounds while excluding experiences from marginalized individuals based on which individuals or communities are chosen to interview and gain knowledge from (Trainor \& Graue, 2013).

\subsubsection{Summary and Frequency Tables}

In order to highlight the results, summary tables were created that highlight each theme's ranking. The two tables (Chapter 4. Table 2, and Table 4) reflect how the overarching themes of procedural equity and distributional equity are broken up into sub-themes. Each sub-theme is ranked according to the quantity in which they appear and the quality or way in which they are defined and operationalized in each municipal sustainability plan. Within each table there is a ranking from 1-4 which represents the presence and strength of each theme within the plan. This process of analysis is used within Schrock et al's (2015) study, where instead of a range from 1-4 they used a 0-3 scale. They also looked at specificity and prominence of each equity theme (pg. 286). I determined the 'strength' of a theme based on the degree to which proposed initiatives and/or goals within the sustainability plans had the following attributes: specificity or clear definition, and a detailed explanation of implementation strategies. Moreover, this analysis seeks to explain the challenges and best practices related to the specificity and implementation of each sub-theme through analyzing qualitative insights from the discourse of the plans themselves, in addition to insight gained from the key informant interviews. 
To be clear, when considering implementation strategies, I am examining this in relation to each specific sub-theme and related goals or initiatives, as opposed to the implementation strategy of the entire ICSP as a whole. It should be noted that within York Region's ICSP one of their themes and subsequent action items is implementation; they state within their plan that they want to produce an implementation action plan that sets targets for monitoring and evaluation (pg.22). Thus, instead of having implementation strategies integrated within their plan they made it one of their priorities to create an action plan. However, an updated action plan was not found to analyze for this thesis.

A ranking of ' 1 ' represents the lowest presence and strength of that particular sub-theme where 4 represents the highest presence and strength. A ranking of " 1 " was assigned if there was no appearance of that specific theme within the document; "2" represents if the sustainability plan had 'some' reference to that theme and/or initiatives and goals that were not particularly strong according to the above-mentioned attributes. A ranking of " 3 " indicates a sustainability plan that had a couple different examples of the particular theme in question, and goals and initiatives were quite strongly articulated. Finally, "4" signifies a sustainability plan that had many examples of the specific theme and they were all strongly articulated examples according to the above outlined criteria.

Table 3 and Table 5 are frequency tables. They break-down the number of times each code was found within the Integrated Community Sustainability Plans. The frequency table helps inform the ranking (1-4) that each ICSP receives for every code (Tables 3,5). However, frequency is not the sole influence on the ranking; quality and strength of the code is also a large aspect of the ranking. Thus, an ICSP may have a high frequency number of a certain code yet not 
necessarily end up with a high overall ranking of that code due to weak specificity and ambiguous detail with respect to implementation.

\subsection{Chapter Conclusion}

This chapter outlined the methodological process of the study being conducted. This study is using the qualitative methods of a document analysis and semi-structured interviews to help answer the research questions of whether ICSPs in Ontario address equity and how the variation of community involvement influence how equity is addressed within the Sustainability Plans. The analysis involves a case study of six Ontario ICSPs, (Table 1) that were chosen through the University of Alberta Canadian Sustainability Plan Inventory using a set of key variables. Open codes were created through an inductive and deductive approach to analyse the six ICSP

documents, which was further complemented by eight semi-structured key informant interviews that provided further insight on the results found through the document analysis. 


\section{CHAPTER 4: RESULTS \& INTERPRETATIONS}

\subsection{Introduction}

This chapter will outline the results and key findings found in both the document analysis of the six municipal sustainability plans, as well as the key informant interviews that were conducted. The chapter begins with detailing the results from the document analysis with emphasis on the presence or absence of two thematic categories: procedural equity, distributional equity and their various sub-themes. Following this, results from the key informant interviews will be discussed. This analysis shows that social equity principles were not prioritized for the majority of municipalities that had created ICSPs and other sustainability plan variants. Even with the federal requirement to consider both social and cultural sustainability (Infrastructure Canada 2008) the results show that very little prioritization and strong active commitment was given to these two dimensions of sustainability. As will be shown, this lack of prioritization of strong social and cultural dimensions of sustainability leads to little engagement with equity principles.

\subsection{Document Analysis}

The two different thematic categories: distributional equity, and procedural equity are represented in the two tables below (Table 2, Table 4). Procedural equity (represented in Table 2) focuses on "the right of all people to participate in environmental decision making", whereas distributional equity (represented in Table 4) focuses on how "environmental benefits and burdens [are] distributed across places and people" (Pearsall \& Pierce, 2010, pg.571). 
Table 2 Strength and Presence of Procedural Equity Codes in SPS

Strength and Presence of Procedural Equity Codes in SPs

\begin{tabular}{|c|c|c|c|c|c|c|c|c|}
\hline \multirow[t]{2}{*}{ Plans } & \multicolumn{4}{|c|}{ Accessibility* } & \multicolumn{4}{|c|}{ Public Engagement } \\
\hline & 1 & 2 & 3 & 4 & 1 & 2 & 3 & 4 \\
\hline Kingston & & & X & & & & & X \\
\hline Markham & & & & $X$ & & & & $\mathrm{X}$ \\
\hline Ajax & & & & $\mathrm{X}$ & & & $\mathrm{X}$ & \\
\hline Greater Sudbury & $\mathrm{X}$ & & & & & $\mathrm{X}$ & & \\
\hline $\begin{array}{r}\text { Frontenac } \\
\text { County }\end{array}$ & & & & $\mathrm{X}$ & & & & X \\
\hline York Region & & & $\mathrm{X}$ & & & $\mathrm{X}$ & & \\
\hline
\end{tabular}

Table 3 Frequency of Procedural Equity Codes

\section{Frequency Table of Procedural Equity Codes}

\begin{tabular}{|l|l|l|} 
Plans & Accessibility* & Public engagement \\
Kingston & & \\
\cline { 2 - 3 } Markham & 8 & 28 \\
\cline { 2 - 3 } Ajax & 24 & 41 \\
Greater Sudbury & 3 & 27 \\
\cline { 2 - 3 } Frontenac County & 8 & 13 \\
\cline { 2 - 3 } York Region & 6 & 37 \\
\cline { 2 - 3 } & &
\end{tabular}


Table 4 Strength and Presence of Distributional Equity Codes in SPS

Strength and Presence of Distributional Equity Codes in SPs

\begin{tabular}{|c|c|c|c|c|c|c|c|c|c|c|c|c|c|c|c|c|}
\hline \multirow[t]{2}{*}{ Plans } & \multicolumn{4}{|c|}{$\begin{array}{l}\text { Community } \\
\text { Focused Projects }\end{array}$} & \multicolumn{4}{|c|}{$\begin{array}{l}\text { Focus on } \\
\text { Marginalized Pop. }\end{array}$} & \multicolumn{4}{|c|}{$\begin{array}{l}\text { Measurements } \\
\text { based on } \\
\text { Aggregate Pop. }\end{array}$} & \multicolumn{4}{|c|}{$\begin{array}{l}\text { Measurements based } \\
\text { on community/pop. }\end{array}$} \\
\hline & 1 & 2 & 3 & 4 & 1 & 2 & 3 & 4 & 1 & 2 & 3 & 4 & 1 & 2 & 3 & 4 \\
\hline Kingston & & & $\mathrm{X}$ & & & & $\mathrm{X}$ & & & & $\mathrm{X}$ & & & & $\mathrm{X}$ & \\
\hline Markham & & & & $\mathrm{X}$ & & & & $\mathrm{X}$ & & & $\mathrm{X}$ & & & & & $\mathrm{X}$ \\
\hline $\operatorname{Ajax}$ & & & & $X$ & & & & $\mathrm{X}$ & & & & $\mathrm{X}$ & $\mathrm{X}$ & & & \\
\hline Greater Sudbury & $\mathrm{X}$ & & & & $\mathrm{X}$ & & & & $\mathrm{X}$ & & & & $\mathrm{X}$ & & & \\
\hline Frontenac County & & $\mathrm{X}$ & & & & $\mathrm{X}$ & & & & & $\mathrm{X}$ & & $\mathrm{X}$ & & & \\
\hline York Region & & & $\mathrm{X}$ & & & $\mathrm{X}$ & & & & & $\mathrm{X}$ & & $\mathrm{X}$ & & & \\
\hline
\end{tabular}

Table 5 Frequency Table for Distributional Equity Codes

Frequency Table of Distributional Equity Sub-Codes

\begin{tabular}{|c|c|c|c|c|}
\hline Plans & $\begin{array}{l}\text { Community } \\
\text { focused projects }\end{array}$ & $\begin{array}{l}\text { Marginalized } \\
\text { Pop. Focused } \\
\text { projects }\end{array}$ & $\begin{array}{l}\text { Measurement } \\
\text { based on aggregate }\end{array}$ & $\begin{array}{l}\text { Measurements } \\
\text { based on } \\
\text { community or } \\
\text { population }\end{array}$ \\
\hline Kingston & 24 & 21 & 38 & 4 \\
\hline Markham & 60 & 28 & 43 & 6 \\
\hline Ajax & 45 & 28 & 45 & 2 \\
\hline Greater Sudbury & 14 & 0 & 0 & 0 \\
\hline Frontenac County & 16 & 3 & 42 & 4 \\
\hline York Region & 14 & 13 & 0 & 0 \\
\hline
\end{tabular}




\subsubsection{Procedural Equity}

Within the thematic category of Procedural Equity different sub-themes were analyzed (See

Table 6 for sub-themes and definitions). Procedural equity, within the environmental justice

framework, is defined as, the right off all people to be part of and have access to public decision

making. The sub-themes included are accessibility and public engagement.

Table 6 Definitions of Procedural Equity Themes

\begin{tabular}{|l|l|}
\hline Definitions of Procedural Equity Themes & Definitions \\
\hline Sub-Themes & $\begin{array}{l}\text { Does the goal or initiative consider accessibility? } \\
\text { Who is the project accessible for? Are accessibility } \\
\text { barriers considered? }\end{array}$ \\
\hline Accessibility/ Access To* & $\begin{array}{l}\text { Highlights ways in which the community is involved } \\
\text { with the formation, planning, implementation of the } \\
\text { Sustainability plan. Goals and initiatives consider } \\
\text { how the community will be involved. Includes } \\
\text { collaboration and partnerships with community } \\
\text { members. As well as opportunities for feedback and } \\
\text { consultation from the public. }\end{array}$ \\
\hline
\end{tabular}

\subsubsection{Accessibility}

The theme Accessibility looks at whether the sustainability plans have initiatives or goals within them that are sensitive to, and focused on strengthening accessibility. Accessibility can be operationalized in different ways, with consideration given to whether people find it accessible to participate in and/or influence community government and decision-making, to ensuring that all people regardless of social and physical mobility are able to access and use all services/environments/infrastructures etc. available around their communities. While these 
themes are being considered within the context of procedural equity, there are many implications for distributional equity as well.

The City of Markham, Frontenac County and the Town of Ajax were all designated a ranking of 4, meaning a very high presence and strong level of detail was devoted towards the concept of accessibility across various initiatives outlined within the ICSPs. York Region and The City of Kingston received a ranking of 3 and the City of Sudbury ranked 1 (due to relatively limited or non-existent levels of consideration given towards accessibility). As stated above, 'strength' is based on evidence of specificity and clear definitions being provided in relation to specific goals, in addition to evidence of detailed explanations of implementation strategies. The following section will show the range of attention given to concerns related to accessibility within the sustainability plans analyzed.

\section{Specificity of Accessibility theme}

There is a wide range of variance in levels of specificity of the accessibility code. Almost all of the plans acknowledge the importance of accessibility within them. All of the plans except for Sudbury have specific goals attuned to addressing different kinds of accessibility factors however there is a range with respect to the degree of specificity provided for each goal.

The wide range of specificity provided is particularly evident within the context of transit and transportation access, given that all six sustainability plans spoke to this issue. Frontenac County states that they are working on implementing the recommendations from their previous Transportation Collaborative Plan of Action (2009), which includes promoting better transit for people that do not have access to other means of travel (e.g. private automobile). Frontenac County goes into detail in identifying specific mobility needs when articulating their goal of providing, "better coordinated transportation service for clients/residents who cannot otherwise 
travel for medical appointments, recreation, educational/social programs, employment training, and shopping for necessities" (pg. 8). They also list the potential organizations they will be working with to accessible mobility, such as Northern Frontenac Community Services, Southern Frontenac Community Services, South East Local Health Integration Network (etc.) (pg.8). This indicates strong specificity in that they articulate why accessibility is important, and who will be involved in implementing identified goals.

On a more moderate level, York Region simply states that one of their goals is to "ensure that all residents and employees, including new immigrants, the elderly, young people and the disabled have barrier-free, accessible and affordable transportation" (pg.13). While this goal specifically acknowledges that there are different accessibility needs within the community, it does not give any specific details on how they will move forward in achieving this goal. Kingston, Ajax and Sudbury have very similar accessible transportation statements in that they do not specifically talk about accessibility within them, but it can be inferred. For example, Ajax states that one of their potential actions is to "encourage ridership, by increasing bus frequency, reducing transit fares, and occasionally offering free services" (pg.73). However, Ajax was much more explicit for other accessibility issues outside of transportation, which is why they received a ranking of 4. Kingston's sustainability plan states that they want to "plan, construct, and maintain safe, secure, convenient efficient and attractive transportation infrastructure to encourage pedestrian cycling and public transit modes of transportation $[\ldots]$ and increase the number of passengers using public transit" (pg.26). Sudbury's sustainability plan merely states that they want an increase in transit ridership per capita. None of these goals specifically talk about accessibility, however their want for increased ridership is intrinsically tied to more accessible transportation for people. Markham ranked amongst the highest, within this analysis, 
given they had very strong specificity. For example, with respect to transit Markham's sustainability plan had a whole section dedicated to "Access and Mobility" (pg. 68) which included giving attention to accessibility within the context of improving active transportation, in addition to public transportation acknowledging that "accessible and affordable transportation choices provide options for people of different means, abilities and ages" (pg.74).

Aside from transportation, Markham, Ajax, and Frontenac County, have many more initiatives that specifically focus on accessibility. For example, in Markham's ICSP they state that they want to work with different levels of government to "facilitate an affordable housing and transportation strategy and proactively design a range of housing and transportation options that can be accessed by all" (Markham ICSP, 2011). Across different goals and initiatives text was devoted to talking about how different organizations and community members can have access and help in implementing each goal. For instance, one option they suggest is that individuals and community groups can help "create resource centres in schools' libraries and communities' centres where goods and services can be exchanged, reclaimed or recycled by residence" (pg. 28). In addition, attention was given to ensuring that there is equal access to different services and decision making within Markham, for example it is stated in the plan that Markham wants to,

develop a community engagement policy that encourages the participation of all demographic groups in decision making and can provide classes to residents about how a municipal government functions and how to get involved in the decision-making process (pg. 29).

However, Markham ICSP did not state who they would get involved with.

Frontenac County also received the ranking of 4 because they also have a very high strength and presence of different initiatives that pertain to accessibility, beyond their 
transportation improvement initiative that was previously mentioned. For example, they are also working on improving internet access to their residents with the goal of moving towards equal access:

Limited broadband service to Frontenac residents and businesses restricts access overall, prevents current businesses from expanding into online marketing and, in some cases, prohibits the establishment of new and home-based businesses. The view of many stakeholders, supported by research, is that access to quality broadband service would be a benefit by providing local residents, organizations and businesses with improved access to training, e-business, e-health, and other essential services - hence increasing local and regional capacity. A series of initiatives have improved service over the last few years including a project that expanded service to all schools in the public-school board area through either high speed fibre or fixed point wireless connectivity.

(Frontenac County ICSP 2010)

The Town Ajax also received a ranking of 4 due to their many different initiatives that are centered around accessibility. For instance, they have a few different initiatives and goals surrounding improving the accessibility of education. The ICSP states that Ajax wants to "Improve the accessibility and affordability of online education [and] provide educational opportunities that match the needs of residents and respond to needs in new and emerging sectors" (Ajax ICSP, 2012). They have accessibility initiatives for different topics like affordable access to nutritious food, and more equitable access to greenspace and recreation facilities. For instance, they state they want to "increase access to food that is affordable, nutritious [and] that is locally or regionally produced" (pg.47).

\section{Implementation of Accessibility theme}

Similar to the wide range of levels of specificity within the accessibility initiatives and goals, there is a large range of implementation strategies. Some of the sustainability plans state very specific implementation strategies, whereas others are very vague, and just state their goals without any strategies. 
Markham's ICSP is formatted in a way that integrates implementation strategies for all their initiatives and goals. Their plan will state their objective like "Promote and support the physical and mental health of Markham's citizens" (Pg. 44), and break down what actions the municipality, business organizations, community groups and individuals can take to accomplish this objective. For example, with respect to specific actions that the municipality can take to support the physical and mental health of citizens, the plan states that the government should: build on and continue to provide an accessible and safe public realm that encourages residents to use active transportation modes and to gather and connect with neighbors year-round. It can provide access to all public facilities and programs for Markham residents regardless of means or ability and can use such facilities to assist residents in times of need. Markham can also implement non-smoking and healthy food policies at municipal facilities and increase its social planning capacity by integrating new social activities not currently being offered.

(Markham ICSP, 2011, pg. 44)

Nevertheless, it should be noted that even though the goal of accessibility is clearly stated and prioritized within Markham's ICSP, there is no real discussion of implementation strategies specifically related to the how they will make their 'public realm' more accessible. Instead emphasis is placed on explaining the benefits. This is still very limited detail within their implementation strategies, for they do not give specific information on how they will actually go about making these things actionable.

Similarly, to Markham, the format of The Town of Ajax and Frontenac County's ICSP aids them in outlining their implementation strategy. Within Ajax's ICSP they have an overarching implementation strategy, similar to Markham's approach, and then they list potential actions to achieve that strategy, including who is leading and who is a partner in achieving these actions. The have the following category of actors leading: The Town of Ajax, community groups, institutions or other business, and other levels of government. However, they do not go 
into specifics of what community groups or organizations they worked with. For example, they have a strategy that states that they want to "encourage, celebrate, and promote diversity of arts and culture that are accessible to everyone" (pg. 29). Their proposed actions for achieving this goal are in Figure 2, which shows how they broke down the three different categories.

Figure 2 Example of Ajax's Arts and Culture potential action table Adapted from Ajax ICSP (2012)

Strategy 2: Encourage, celebrate and promote a diversity of arts and culture that are accessible to everyone.

\begin{tabular}{|c|c|c|c|}
\hline Potential Actions & $\begin{array}{l}\text { Town } \\
\text { of Ajax }\end{array}$ & $\begin{array}{l}\text { Community Groups } \\
\text { institutions or } \\
\text { Business }\end{array}$ & $\begin{array}{l}\text { Other } \\
\text { levels of } \\
\text { government }\end{array}$ \\
\hline $\begin{array}{c}\text { Assist in the organization, promotion, and } \\
\text { continued success of community events, } \\
\text { festivals, and celebrations }\end{array}$ & Lead & Partner & \\
\hline $\begin{array}{l}\text { Incorporate art and culture into significant } \\
\text { festivals and events (e.g. Earth Day)* }\end{array}$ & Partner & Partner & \\
\hline $\begin{array}{r}\text { Explore creating a permanent bandshell in } \\
\text { Ajax to facilitate performances* }\end{array}$ & Lead & & \\
\hline $\begin{array}{l}\text { Create a cultural/arts centre in the Pickering } \\
\text { Village area dedicated to visual arts*. }\end{array}$ & Lead & Partner & \\
\hline
\end{tabular}

Frontenac County has a very similar set up, in that for each of their initiatives they outline who will be leading, who the anticipated partners are, the status of identified initiatives, estimated timeframes and cost, and potential funding source (Figure 3). This, like Markham, and Ajax inherently makes their implementation strategies stronger because they attempt to outline how they would be moving forward with their goals. 
Figure 3 Picture of Frontenac County Act on Recommendations of Frontenac Transportation Collaborative

\author{
3.1.4 Act on Recommendations of \\ Frontenac Transportation Collaborative \\ Pillars: Social/Cultural/Economic \\ Focus Areas: Health and Social Services, \\ Housing, Transportation \\ Action on the recommendations of the Frontenac \\ Transportation Collaborative Plan of Action is \\ suggested to ensure a more sustainable, better \\ coordinated transportation service for clients/residents \\ who cannot otherwise travel for medical appointments, \\ recreation, educational/social programs, employment \\ training, and shopping for necessities. \\ Lead: County of Frontenac in association \\ with transportation service providers \\ Anticipated Partners: Northern Frontenac Community \\ Services, Southern Frontenac Community Services, \\ South East Local Health Integration Network, \\ Provincial Ministries, City of Kingston, et al. \\ Status: Proposed \\ Timeframe: Immediate \\ Cost: To be determined \\ Potential Funding Sources: Federal Gas Tax funds, \\ Provincial Gas Tax funds
}

York Region's sustainability plan and The City of Kingston both have weaker implementation strategies for accessibility resulting in both of these ICSPs receiving a ranking of 3. They both had initiatives and goals that specifically looked at accessibility, yet they did not have the same detail of implementation strategies that the three other plans had. York Region had stated goals for improving accessibility, however they did not have many specifics when it came to detailing implementation strategies or initiatives in comparison to the other plans. Similarly, The City of Kingston states that accessibility is one of the foundational themes of their ICSP, and that accessibility as a key component of many of their initiatives. For example, they state "Our actions and implementation plan will promote accessibility and equity in order to address the 
diversity of needs based on age, gender, cultural backgrounds, and abilities" (Sustainable Kingston, 2010). Yet they do not have implementation strategies for the identified goals within their ICSP. For instance, they have a goal that states they want to "enhance access to healthy food choices" (pg.38) but within their plan they do not outline how they will be doing that, or what actions they will take. The plan does state that they have created a website where Sustainable Kingston Partners can post about the actions, they are contributing to in implementing the actions of this ICSP, but the plan itself does not go into any further implementation strategies.

Further insight about Kingston's accessibility objectives and implementation approach was acquired when interviewing the Community Engagement Specialist at Sustainable Kingston on the arms-length organization put in charge of implementing the Kingston ICSP. The interview was conducted on July $3^{\text {rd }} 2019$. They explained how they try and make all of their events accessible:

"I try to make all of our events as accessible as possible, so this includes venue selection making sure it is wheelchair accessible. When we have slides or even on our website making sure text is accessible. We have had water bowls for service dogs at our events. We try to post it on multiple platforms like radio versus online, and use because if all our events are accessible people associate that with us as well and can talk to us in different areas whether that is our office or hosting an event in a different part of town or the university or wherever".

The City of Sudbury does not specifically talk about accessibility aside from stating they want to increase transit ridership other than a very general statement about wanting to create opportunities for all of Sudbury. Further, The City of Sudbury follows a similar approach as Markham and Ajax in that they outline their objectives and outline which actions will be taken to complete that objective. Yet their approach lacks the same amount of detail regarding 
implementation strategies as the other two sustainability plans. They only delegate their actions to "Earth Care Sudbury Partners", a broad coalition that encompasses the municipal government, organizations, businesses, and other institutions. Their action items do not provide further detail on implementation strategies, as seen within the other plans.

\section{Summary of Results}

The theme of accessibility is operationalized differently across municipalities with a large variance in how the theme is specified or the level of detail provided for associated implementation strategies. Overall the plans identify accessibility issues in fairly specific ways yet are less thorough when it comes to outlining implementation strategies on how to achieve the accessible goals and initiatives that have been created. All the plans except for Sudbury have very specific goals relating to accessibility, however only Markham, Frontenac, and Ajax have stronger implementation methods revolving around the accessibility theme. Even in the cases of these latter three, implementation methods do not necessarily give detailed strategies in how further and stronger accessibility will be achieved, but they give more detail surrounding implementation strategies than the latter. Thus, there is still a large room for improvement within both the specificity and implementation strategies within each of these plans.

\subsubsection{Public Engagement}

The theme public engagement as defined in Table 7, looks at ways in which the community is involved with the formation, planning, and implementation of the Sustainability plan, and/or looks at the goals and initiatives that address how the community will be involved within the process. This theme focuses on whether the sustainability plan identifies if the public had the ability to participate through consultation and the ability for community members to be a part of 
the implementation of projects through engagement or partnerships, both at an individual or organizational level. All of the plans, to some extent, engage with the theme public engagement, yet there is clear differences in how each plan engages with this theme. The City of Markham, Kingston, and Frontenac County all indicated that they were devoting significant attention to citizen \& community engagement and consultation, giving them a ranking of 4 . The Town of Ajax received a ranking of 3 whereas the lowest ranking for the citizen engagement code was a 2 from York Region and The City of Sudbury because they had the least consideration of these themes and weak or vague illustrative examples.

\section{Specificity for Public Engagement theme}

As stated above, all six of the sustainability plans mention community engagement to some extent. Where the biggest difference of strength is in the level of specificity of how each plan outlines their engagement and consultation process

The city of Markham received the ranking of 4 because within the ICSP, citizen engagement is talked about extensively. They state that one of the main goals for Markham's ICSP is community engagement and collaborating with different communities to get different input and perspectives. One of their goals was that they would create a community engagement strategy that will ensure "consistency in engagement approaches as well as meaningful community participation in all initiatives" (Markham ICSP, 2011).

Further, Markham's ICSP highlights community partnerships as being essential to the promotion of social equity, culture and identity, individual human health, food security, and access and mobility. The City of Markham lists a lot of potential partners from different organizations around Markham and the GTA including: The United Way, York Community Foundation, different ethnic organizations, and different school boards. 
The City of Markham also devoted significant attention to community feedback.

Throughout their plan they showcased that they have set up different public meetings for various projects like creating the ICSP, and education on energy, water and waste reduction. They even state where and when their consultations were held, being very thorough with details. For example:

A draft of the Greenprint was prepared and launched for extensive community consultation in June 2010 at the Unionville Festival. A rigorous consultation process followed that included 27 community meetings and events in addition to consulting all commissions and departments at Markham via 32 staff meetings (Markham ICSP, 2011).

As well within their ICSP Markham speaks about how a, series of resident and stakeholder workshops were held from late 2009 to early $2010 \ldots$... and] that in 2009 more than 100 local and regional stakeholders participated in a workshop to review Markham's twelve sustainability priorities and to develop strategies for how each priority could be achieved

(Markham ICSP, 2011),

In addition to the many public consultation meetings they outline four different processes they used to receive public feedback. For example, they had two large events in 2008 to help create the sustainability plan including a youth engagement contest in 2008 where over 2000 ideas were shared on how to improve the city, in addition to hosting a World Café which is an event that allows for collaborative dialogue based on different themes and ideas relating to sustainability and improving the city. In 2009 they held a sustainability fair for residents to discuss and give feedback on the 12 priorities that were chosen, as well in 2009-2010 stakeholder workshops were held where over 100 local and regional stakeholders reviewed the 12 priorities chosen. However, there was no information in the plan on who those stakeholders were. Nevertheless, the plans transparency and extensiveness in detailing the feedback suggests that there was a very strong 
community feedback process. This was further verified when interviewing the Sustainability

Manager for The City of Markham, on July $18^{\text {th }} 2019$, who stated:

we would bring in external and internal stakeholders to come in and have whole day workshops, I believe we held two of them. And to essentially understand what sustainability meant for everyone and how we can come to common grounds to leverage that commonality in our plans. So, it speaks [the sustainability plan] to not just Markham as a municipal government, but all our community members as well

Yet, it should be noted that when asked about how the ICSP could have been improved, the same Sustainability Manager replied:

"If we were to do this again, it would consider more consultation with different stakeholders, the same way we do that we do with the Markham Energy Plan [currently]. What I mean by different it ranges from residents down to local business, industrial, institutional. As many programs we can to get the different perspective of sustainability from all of them"

They went on to suggest that they would have also benefitted from a "stronger youth presence that is something we try to work on engaging our youth in sustainability"

Additionally, when asked about the demographics involved in community engagement, and whether any communities were excluded or underrepresented, the Sustainability Manager from Markham City replied:

I wouldn't say we excluded anyone in particular, definitely not on purpose, I would say we would have benefited from a stronger youth presence that is something we try to work on engaging our youth in sustainability and youth were invited, it was an open dialogue for them to join the energy plan. But I don't think they understood it maybe per se on what we were trying to achieve, or maybe [it was the] timing of high school students and exams. But I think we could have pushed that a little more and involved their ideas for the municipal energy plan

This quote is quite significant because it shows that there is some level of awareness from the sustainability manager in The City of Markham about ensuring that community participation comes from all types of community members. It shows that if in future sustainability plans were to be created again that maybe there would be more encompassing community engagement. 
Kingston's ICSP is very interesting in that their plan states that community ownership is a core principle and fundamental to the success of the plan, and they have shifted the implementation of their sustainability plan to an 'arms-length' non-profit corporation Sustainable Kingston Corporation. They proclaim, "The Sustainable Kingston Plan will be implemented within the community and is not a project or program of the City of Kingston - though the city will be a partner in pursuing its goals. Although striving for community ownership adds to the complexity of implementing the Plan, ultimately it will make it stronger" (Sustainable Kingston, 2010). This focus on community engagement was reiterated in an interview conducted with The City of Kingston's Environmental Director, on June $26^{\text {th }} 2019$, who stated:

There was a big focus on community ownership over the plan. This was not supposed to be just another municipal plan, it had a new implementation approach that focused on the community ownership of this plan

And further went on to explain,

With this new plan we wanted to move away from the city departments having complete control. We created a municipal arm's length corporation to own and implement the plan. This was the Sustainable Kingston Corporation. This was done in order to make the plan community owned, and not just keep it in the hands of the municipality" [...] We realized to be a truly sustainable community we couldn't put the implementation load entirely on the municipal corporation because that wouldn't be casting the net wide enough, so we were able to develop a number of action areas, things like improving public transit increasing supply of housing, wage equity issue, local food security issue, and the connection between arts and cultural and local economic development. Those were all identified as important, and of course the reduction of community GHG through things like active transportation and public transportation, electric vehicles, land use planning. Those all came to the floor through consultations that were reflected in the plan.

The Sustainability Kingston Corporation is still active in pursing sustainability goals for Kingston; however, it has now deviated from just implementing the Kingston ICSP (more information about the Sustainability Kingston Corporation and how it runs is discussed in Section 5.4). During an interview with the Community Engagement Specialist that works for the 
Sustainable Kingston Corporation, I asked about community engagement and the type of events held. They replied:

They're generally education-based events, as all of the workshops [that are run by Sustainable Kingston, each focusing on a different sustainability theme] are also open to the public. When it comes to more specific things, we generally work more one on one with our members, or sometimes different organizations will each out to us, in hopes we can work together to host a workshop. So, it is kind of also based on that opportunity and need.

However, in terms of community consultation the plan does not go into a tremendous amount of detail explaining the impact of their community consultation meetings nor gives details of when and where they were held. One of their foundational principles and objectives is to "become a conduit for community input and a catalyst for discussion that will result in the development of a community owned and community involved process that is tailored to the unique needs and desires of Kingston" (Sustainable Kingston, 2010). Thus, they did not disclose the process of community consultation like Markham and Frontenac County. During an interview the City of Kingston's Environmental Director provided some additional insight:

We had the usual demographic that we would see in terms of municipal consultation, that is the older crowd, but we also recognize that was going to be a problem we didn't just want to have that voice, so we specifically went out and did a number of consultation at Queens University and St. Lawrence college campus, so we had quite a number of younger folk attending and giving a voice that way as well.

Frontenac County's ICSP also has a ranking of 4 for their presence and strength of the public engagement themes within their plan. Frontenac County acknowledged that they cannot have successful sustainability planning and development within their community if they do not have community engagement and participation. The Frontenac ICSP was created through consultation and participation from the community. They disclose that more than 400 
stakeholders offered their time and resources to meet, comment, and provide insight (Frontenac County ICSP, 2009). Through this community engagement 40 new sustainability projects were then recommended and put in front of the regional council to approve. Thus, all the initiatives within the plan are ones that the broader community has come up with. As well, throughout the plan each initiative is broken down and says who is leading, and any anticipated partners. Having this degree of detail in figuring out which initiatives organizations should be partnered with, and who should be leading certain objectives helps in showing that Frontenac County was prioritizing community engagement and partnerships throughout the planning and implementation process.

Frontenac County's ICSP gave a very detailed account of how they integrated and relied on community consultation for the creation and implementation of their plan. The plan goes into great detail and is very transparent about their community consultation, it gives the dates of different consultation meetings they held as well how they advertised for the meetings. There are also summaries on the amount of feedback they received during different consultation methods. For example, it states that "a county newsletter, Municipal Matters, introduced the ICSP to each household in Frontenac County by direct mail. By early 2009, over 80 submissions through the website provided insight and additional voice to the community consultation process" (Frontenac ICSP, 2009). As well they created a sustainability website and surveys for the community which:

provides regular updates and all reports on sustainability in the Frontenac's and plays a lead role in communications with stakeholders, the public and interested parties from both inside and outside the County. [As well] It provides an ongoing record of stakeholder responses including feedback, project suggestions and contact information from more than 300 stakeholders who are actively engaged. (Frontenac ICSP 2009) 
Further, they outline that they had consultation meetings with the councils of all 4 townships within their regional jurisdiction, they held meetings, sent out questionnaires and collected data from the townships, which provided the foundation for the development of the ICSP. Lastly within the appendix of Frontenac County's plan they outline all the projects that were recommended by the community and stakeholders through all their different consultation methods. It is this attention to detail and transparency which shows that they have a very strong community feedback process and opportunity for citizen to engage with the sustainability plan. Further insight on the extensiveness of the community feedback opportunities within the County were found during interviews. When interviewing the Director of Planning and Economic Development of Frontenac County, on July $31^{\text {st }} 2019$, I asked whether they thought any populations were underrepresented or excluded. They stated:

No, I don't, the outreach was extensive, we certainly reached out to the Algonquin community because that is the primary because almost all of the Frontenac county with the exception of the island is in the Algonquin land claim. There are two bands within our county, and I know that they were involved, and they were supportive. I mean they think 7 generations, for them to see a document that showed we are looking 50 years ahead, they thought that was a very positive thing.

When asked about the process of public engagement and participation in the creation of the ICSP they stated that,

I can say that in the 30 years I've been practicing planning this was one of the most comprehensive outreaches I was a part of. It was not tokenistic at all, it was consensus building and at the end of the process I felt that our county council really had no choice to approve the plan because they were aware the large amount of public consultation it has taken to put it together.

As well, when answering questions about the diversity of citizen engagement with the ICSP they stated 
I do recall that we made sure that we covered the entire geography, we had a lot of meetings a lot of places, there wasn't just a meeting just in Chabert lake, right beside highway 7, one of Frontenac biggest communities. We did not just have meetings there, there was meetings in community halls, there was meetings with the Algonquins in their kitchens, there was meetings at the legions. All four seasons. And my understanding was, once it got underway and people got involved those people got people involved.

However, they did note there were some challenges with diversity in community engagement, when asked about who all participated, they said that

I can't say it was everyone, again I can't give you a lot of detail, the biggest challenge on consultation on any planning issue or any issue where you are trying to think of the future is getting the youth involved. And I don't think that happened in the sustainability plan. And when I attended the sustainability breakfast the first couple of years, and saw the people involved with the plan, there was a lot of retired people. There wasn't a lot of young people, there was a couple of young farmers, some businesspeople. But by in large it was an older demographic that was primarily involved in this plan.

The Town Ajax received a ranking of 3 for how they address the theme, even though community engagement is a large foundation of their sustainability plan. They do not have as many specific details in their plans of what the engagement and consultation process looked like, as well their implementation of public engagement was weaker. Community engagement is at the core of the Ajax's ICSP, they state that community engagement and participation is a key principle in creating a sustainability plan. Within the ICSP they outline that when developing their plan, they had key community stakeholders such as residents, community groups, businesses, service agents etc. discuss, debate and review the identified issues of importance for the formation of the plan.

The Town of Ajax also had strong community feedback initiatives outlined throughout their plan, highlight that they see the importance community engagement and consultation however they do not provide much detail on their feedback and consultation process. The plan states that: "There are fifteen areas that the community and Town staff identified as relevant and 
significant during our conversations" (Sustainable Ajax 2013). Within the introduction of the plan it is stated that "nearly 2000 people provided their thoughts on how to make Ajax more sustainable. Of those nearly 2,000 people more than 800 made a pledge to take actions that contribute to our community's sustainability" (pg.9). This is a great breakdown of participation, it gives real measurable numbers to see how many people contributed to the plan, which can help in understanding the communities input and the degree in which the community was engaged with the sustainability plan. However, it is worth noting that without stating or clarifying who those people participating were socio-demographically, this limits the ability to ensure that participation and engagement is equitable.

The York Region Sustainability Plan received a ranking of 2 for the public engagement theme. They have overall limited public engagement and consultation opportunities outlined in their plan. Within the plan it states that one of their foundational principles of sustainability is public and stakeholder input and engagement. However, throughout the plan their actions are extremely vague making them rank lower than Ajax, Markham, Kingston, and Frontenac County. The York Region Sustainability Plan does say that they came up with a number of their priority actions outlined in their plan through consultation with the community. Moreover, the plan has a section titled "Education, Engagement and Partnerships", which articulates an understanding that "the strength and resiliency of a community is very much linked to the inclusion and engagement of individuals, community and organizations in community life" (York Region Sustainability Plan, 2010).

Yet there are very few details about public consultation within their ICSP. The last page of the sustainability plan acknowledges that the 
Sustainability Strategy is based on input from the public and stakeholders during the Region's Sustainability Symposium, the Towards Sustainability in York Region (TSYR) Advisory Group and the Growth Management Public Engagement Initiative. We also received valuable feedback from several organizations and individuals during the consultation phase of the preliminary draft. The Sustainability Strategy contains many of the hundreds of ideas that we have heard from the public. (York Region Sustainability Plan, 2007)

However, aside from this one statement about public output and feedback the plan does not go into further detail about the public feedback or consultation process. They do not outline which initiatives the community recommended or what changed due to public feedback. Further there is no confirmation of where or when consultation took place.

This finding of limited public involvement was verified in the interview conducted with a professional planner within the York Region on October $17^{\text {th }} 2019$. When asked about who was a part of the creation for the ICSP they said,

we did have a steering committee [...] We had a Towards York Region and Sustainability Advisory group, also input from our public engagement consultation exercise as a part of our growth management strategy outreach at the time.

Yet, it was confirmed that community engagement was not a driving factor in the creation of the ICSP, for they stated:

In the development of the Sustainability Strategy, public consultation was used to confirm the direction that had been developed, rather than specifically developing recommended actions with them. We used an advisory group, which included members of community stakeholders to produce the strategy with a broader public engagement process to confirm and get some input on our thinking.

They then explained further that,

we go to them [the public] and confirm the direction we have established, with our community partners and stakeholders, rather than them being more closely at the table with us actually driving the actions. 
Furthermore, when commenting on the demographic make-up of the public engagement, or if they thought there were groups being unrepresented or excluded, they stated

Yes, there are. Municipalities have a set of practices they use for public consultation, and there are people disengaged, disenfranchised, or just struggling to live their life, who do not have the luxury in participating in kind of those typical consultation practices. In 2007 I don't think the online platforms were as accessible to everyone as they might be today. I think any time if the municipalities consulting of any kind of plan you have to be cognisant that you are reaching a certain demographic, and the result is that other segments of our population are excluded because they do not have the time or the capacity to participate. I think you should be cognisant of that and do whatever you can to reduce barriers. Online helps instead of just public open housing, going to where people already are.

When further asked about if there were any barriers to community participation within sustainability planning for their region they stated,

I think that the barriers and the issues that would have arisen on the sustainability strategies consultation are the same we experience on land use planning, on transportation projects on really any consultation a public agency is doing.

Sudbury's sustainability plan ranked a 2 . Overall, they acknowledge that citizen \& community engagement and partnerships is crucial for sustainability planning and development, however the plan does not go into great detail about how they will commit and implement meaningful community participation. Unlike the other plans Sudbury's sustainability plan does not go into detail about how the community helped shape the plan or help prioritized the initiatives within it. However, they do have a few initiatives that call for community engagement within them. An example is the development of multi-faceted strategies "to promote efficient energy consumption, link community groups to energy conservation programs, hold public info sessions relating to energy efficiency and renewable power" (EarthCare Sudbury 2010). Moreover, within the plan there is recognition of partners of the Sudbury Sustainability program, and within some initiatives, what roles the partners would be playing within implementation. For 
instance, in the food category under their action section they state that EarthCare Sudbury's

partners will:

- Raise awareness about local food choices,

- Buy food from local producers

- Investigate creating 'farm to institution' partnerships, support the featuring of local food items in Greater Sudbury's Good Food Box program.

(EarthCare Sudbury 2010)

More insight on community engagement was given when interviewing the Coordinator of the Sustainability Program in Sudbury (EarthCare Sudbury) on May $30^{\text {th }}$ 2019. When answering the question about whether they partnered with community members, in addition to organizations in the city, they answered,

We found that most people that were passionate about the environment tended to be part of grassroots or non-profit groups already. For example, many passionate residents are part of our groups like the Coalition for a Liveable Sudbury, Rainbow Routes Association and Rethink Green. In current projects, we try to have some representation from these groups as well as a member of the public that may not be part of these organizations. I'm not sure about how it was done almost 20 years ago when the first plan was developed"

As well when talking about the barriers in community engagement and equity they said,

Many past practices of community engagement have not been effective for certain populations. For example, the typical City event where we ask people to join us, isn't going to reach everyone. For the implementation, we will try to provide different opportunities to engage. For one project, I walked up and down a street to talk to residents and set up a pop-up booth at a popular lunch time store. There can be more examples of how we can reach the more vulnerable populations so that they are aware of the programs that we are offering without requiring them to come to us.

Yet the sustainability only acknowledgment of community feedback and consultation was in their introduction of their plan stating,

While individual actions are important to address environmental issues, it is the collective actions of a community that usually have the biggest impact. For this reason, partner participation was important in updating the Action Plan. Implementation will also continue to be a collaborative effort of the EarthCare Sudbury Partners. To sustain 
Partner and public engagement going forward, EarthCare Sudbury will implement a comprehensive Communication Strategy. The strategy, which is currently being developed, will be separate from this Action Plan, but will revolve around the updated Plan and its key messages.

(EarthCare Sudbury, 2010).

It is understood that the prevalence of community feedback will help increase procedural equity within a community. The ability for people to be able to engage with and in the public sphere is important for ensuring true equity within a community and the greater society.

\section{Implementation for Public Engagement Theme}

As touched upon the in previous section, community engagement was key principle of The City of Markham's ICSP. They talked about their implementation approach stating they held workshops and meetings for people to come, review and provide input into the sustainability plan. As well, throughout the plan after stating a specific initiative related to community engagement, they outlined actions that the community can take to help achieve the goals highlighted. One example of this is in relation to their objective to "improve support to lower income students". They stated that individual and community volunteer groups can "help create resource centers in schools, libraries and community centres where goods and services can be exchanged reclaimed or recycled by residents" (pg.29).

The City of Kingston's community engagement implementation strategy is also outlined extensively within their ICSP. As stated previously, one of the ICSPs goals was to ensure that the sustainability plan is community owned, to ensure full participation and engagement from the community. In order for them to ensure that the sustainability plan is community owned the municipality created a community-based organization that is arms-length away from the municipal government. This organization was created in order to implement the actions and goals within the Kingston ICSP. The plan outlines that they would be doing this through 
Creating awareness of the Plan and the opportunities for citizen commitment and community partnership, maintaining a dynamic inventory of partner actions and their status, continuously improving the Sustainable Kingston Plan through consultation with the community and partners, reporting out on the state of sustainability within Kingston. (Sustainable Kingston, 2010)

In the appendix of Kingston's ICSP it lists many organizations, institutions, and businesses that they have collaborated and partnered with for different events associated with the ICSP.

The Town of Ajax's implementation strategies are displayed in their plan. Within their plan they list the different tools and methods they will use to engage the citizens of Ajax. These include maintaining and updating their website, reconvening the community sustainability team and/ or residents' panel to receive information on certain projects, delivering announcements at municipal public workshops or open houses, doing regular polling of the public to collect feedback on Sustainable Ajax and more. In the appendix of their plan they also outline the mechanisms and organizations used for reaching out to the community for engagement and feedback. The mechanisms included:

- Sustainable Ajax Website

- Sustainability Commitments and Sustainable Ajax Mosaic

- Family Sustainability Project

- Youth Eco Contest

- Sustainability Showcase event

- Sustainable Ajax Day

(Sustainable Ajax, 2013)

These are all different types of mechanisms or projects that Ajax used to reach out to the community members to help spread the word about their sustainability plan and goals. Yet, during the time of collecting data for this study in 2019, there was no one working in Ajax's sustainability department. This can lead into inferences about a lack of capacity to actually implement the sustainability plan (Bos \& Brown 2013) and have active participation and feedback from community members. Thus, for all the strong public engagement initiatives and 
opportunities they have throughout their sustainability plan they are weakened significantly by not having any actual employees to oversee the sustainability plan and department.

Within Frontenac County's plan they explain how they created two 'tools' to ensure good community engagement. Firstly, they created a community partnership agreement which is a formal community agreement that individuals or organizations can sign and agree to, which they argue will help achieve several outcomes including:

- Common ownership of a project or program,

- Commitment to follow a vision, principles or specific actions

- Agreement to a common understanding of sustainability,

- Provision of data to support indicator monitoring,

- Commitment to communicate with clients, customers, employees and visitors about sustainability using common messages

(Frontenac County ICSP, 2009).

Secondly, they created a Memorandum of Understanding, which is "recommended between the County and an individual, community group or organization to clarify relationships when an individual, community group or organization agrees to lead or to support an action that will support sustainability" (Frontenac County ICSP, 2009). This memorandum of understanding is significant because it ensures accountability of both the county and individuals/organizations who are taking part in the sustainability plan. When an organization is going to help achieve a sustainability goal, they fill out this document which outlines their roles and the county's roles, and the details of what will be done. This allows for full transparency and understanding of what is expected of the community member.

The York Region sustainability plan does not outline their implementation strategies in the same level of detail as the other sustainability plans. They merely listed actions under various thematic goals. For example, under the theme of "Education, Engagement and Partnerships" 
examples of implementation strategies include: publish and distribute the sustainability strategy for public stakeholders and partners, produce a citizen's brochure to explain how citizens can contribute to York Regions' goals, promote their social goals of equity, promote and showcase sustainability initiatives at community events, engage businesses, schools, and community groups in on-going discussions about York Region's sustainability strategy. As well they also have an action dedicated to publishing and reporting annually to the public to help keep the community involved. However, they do not outline when/if public engagement meetings will be or have been undertaken.

\section{Summary of Results}

Public engagement has a critical role within procedural equity. The public engagement theme had the most positive results in comparison to accessibility. All six sustainability plans addressed community engagement and consultation within them and overall there was a high level of attention given to community engagement amongst all the plans. All the ICSPs acknowledged the importance of community feedback in trying to achieve their sustainability goals however there was a degree of variance in how detailed and transparent the different ICSPs were in terms of stating and having community feedback opportunities. Markham, Kingston, Frontenac County and Ajax all had many fairly strong outlines of their feedback opportunities within their respective ICSPs, whereas Sudbury and York Region had low appearance of opportunities. The various interviews with representatives from the different municipalities gave some insight on how each municipality was trying to engage with all community members during the creation and implementation of the ICSPs. One notable result was that even though York Region's sustainability plan stated the plan was created using public feedback, insight from 
the interview suggest that public feedback was only used to verify the approach already taken in the sustainability plan and not to help create the initial plan.

\subsubsection{Procedural Equity Conclusion}

For both themes within the procedural equity section, a majority of the ICSPs ranked fairly well. There was an abundance of positive references that addressed different aspects of procedural equity. Noticeably the six different ICSPs were much better at specificity of actions/objectives versus implementation strategies for each theme. There were two plans that ranked pretty low for public engagement, Sudbury and York Region. Community feedback is specifically looking at if the plan outlines opportunities both past and present that allow community members/ individuals to give their input on the sustainability plan, in both the creation and implementation phase.

Moreover, both Sudbury and York Region ranked poorly for having no indication of these opportunities within their plans. Though it should be noted that through the semi-structed interviews further insight was gained about these instances; Sudbury did have meaningful feedback opportunities for the community, and York Region did not use community feedback in creating their ICSP. Public engagement was where most ICSPs performed strongly. This could potentially be associated with the fact that community engagement and participation is one of the federal requirements for ICSPs, as well it is a very agreed upon practice within sustainability planning (Portney, 2003; Infrastructure Canada, 2006; Markvart, 2015). Whereas there is no requirement for accessibility within ICSPs. 


\subsubsection{Distributional Equity}

Within the thematic category of distributional equity, four different sub-themes were considered and analyzed. Distributional equity, within the environmental justice framework, is defined as considering how benefits and burdens are distributed across places and people (Schlosberg, 2007; Pearsall \& Pierce, 2011;Teelucksingh \& Masuda, 2014). The sub-themes within this thematic category include: 1) community focused initiatives, which is looking at whether there are projects/objectives that are focused on a specific community based in space/place or certain groups of people; 2) consideration for marginalized populations; 3) measurements based on populations/community; and 4) measurements based on aggregate. The latter two sub-themes consider whether the plans utilize measures or indicators to track the plans impacts and progress, and if so, are these measures based on specific communities or the aggregate city/community as a whole. All these codes are defined below in Table 7.

Table 7 Definitions of Distributional Equity Themes

\begin{tabular}{|l|l|}
\hline \multicolumn{2}{|l|}{ Definitions of Distributional Equity Themes } \\
\hline Sub-Themes & Definitions \\
\hline Community Focused Initiatives & $\begin{array}{l}\text { Projects/ objectives are focused on specific } \\
\text { communities. }\end{array}$ \\
\hline Consideration for Marginalized populations & $\begin{array}{l}\text { Projects are focused on marginalized } \\
\text { populations }\end{array}$ \\
\hline Measurements based on aggregate & $\begin{array}{l}\text { The indicators are measured using aggregate } \\
\text { totals (e.g. 20\% more green space) }\end{array}$ \\
\hline Measurements based on community/ population & $\begin{array}{l}\text { The indicators are measured based on specific } \\
\text { communities or populations (e.g. Voter turnout } \\
\text { for low income communities increased by 1\%) }\end{array}$ \\
\hline
\end{tabular}




\subsubsection{Community Focused Initiatives}

The Community Focused Initiatives theme analyzes whether sustainability plans have action items developed for specific communities within their municipality/region. An example of this is something along the lines of 'creating a job fair for youth'. This is an example of a specific community, however one that is not necessarily marginalized or disenfranchised. Looking at initiatives that are specifically focused on community groups and not just the city as a whole helps in analyzing distributional equity for it shows if the municipality/region is publicly stating its commitment to developing sustainability initiatives that cater to different needs across a community. Further, this code aids in seeing if there are any communities that are being 'favoured' within sustainability initiatives or goals, and/or whether any are being overlooked or dismissed. For this thesis 'community' is defined as "a unified body of individuals such as...a group of people with common characteristics or interest living together within larger society" (Community, 2020)

The Cities of Kingston, Markham and the Town of Ajax all received a ranking of 4 for their high strength and presence of community focused initiatives. On the opposite end of the spectrum Frontenac County, York Region and The City of Sudbury all received a ranking of 2.

\section{Specificity of Community Focused Initiatives theme}

There is a wide range of different levels of specificity provided on community focused projects/initiatives both between the individual ICSPs across different communities and within each distinct plan themselves. Throughout all the plans there is both very specific community focused initiatives and very ambiguous ones. Due to the fact that plans have both specific and ambiguous initiatives, the ranking of "high strength" also looks at the number of specific initiatives/projects each plan has. 
As stated above, Markham, Ajax, and Kingston articulated very strong community focused initiatives in their plans compared to the other municipalities. All three plans had a significant number of initiatives/projects and goals that were quite specific tangible, actionable and/or paid attention to which sub-populations would be specifically targeted (e.g. youth, seniors). For instance, Markham took the time to explain specific initiatives that would help to address their goal of strengthening youth engagement:

A social media strategy will assist communication with youth. Markham can also build upon the Mayor's Youth Task Force, such as by coordinating a shadow youth council where members of council and staff serve as mentors to engage interested youth in the political process. (Markham ICSP, 2011)

Further, they provided a moderate level of detail about some of their intended actions. For example, they state a commitment to "partner with community groups to support and monitor seniors living alone [and] support programs that allow seniors to continue living with family and within the family home for as long as possible" (Markham ICSP, 2011).

Both Ajax and Kingston are similar with respect to ensuring there is specificity within their expressed goals. Kingston has an initiative stating that they want to "provide financial assistance to children in need so that they may participate in recreation and sports activities" (Sustainable Kingston, 2010). The City of Kingston also has other specific community-based initiatives like starting a website for new immigrants in Kingston, reconstructing and revitalizing certain roads, and increasing sales of local food for the downtown community.

When asked about how certain areas or communities are chosen for sustainability initiatives during a key informant interview, the Environmental Director of The City of Kingston Stated,

I think it wasn't really a product of the Sustainable Kingston plan, but we know that a lot of the social-equity issues the cities needs to deal with resides in a certain area [of the 
city], say the north end. So, I think that, if it wasn't explicit in the plan it was understood. But other than that, I would say, I suppose there were a bit of focus on rural areas especially in the context of economic development of the local food.

The Town of Ajax also had numerous specific goals centered around youth and education. For example, they express a desire to:

Invite youth to economic development initiatives [....] continue to provide students with valuable employment, mentorship and internship experience at the Town. [...] Continue to actively promote the opportunities for youth associated with the Ministry of Economic Development and Trade summer company program. (Sustainable Ajax, 2010).

The Town of Ajax also has specific initiatives around developing a young professionals' network, encouraging the creation of home-based businesses for youth, and providing professional development services.

In comparison, Frontenac County, Sudbury and York Region had fewer specific initiatives described within their plans. Yet, there were some. For example, in relation to youth and senior populations, Frontenac County argued:

Particular emphasis should be considered in relation to understanding medical needs; needs of youth and seniors; linkages and collaboration; access to resources; innovation (such as community paramedicine, telemedicine or nurse practitioners using mobile vans to deliver services).

Overall, the City of Sudbury was limited in articulating initiatives that were focused on specific communities. Yet they did emphasize a specific focus on youth by stating that they want to "seek youth input and participation with community projects $[\ldots .$.$] create green jobs and volunteer$ opportunities for youth" (EarthCare Sudbury, 2010). Similarly, the York Region plan also mentioned a focus on youth and children in general terms stating their intention to "continue to invest in our children through early childhood development and early intervention services" (York Region Sustainability Plan, 2007). The limited attention given to community-based 
initiatives in Sudbury's ICSP was confirmed during an interview with Sudbury's Sustainability Program Coordinator. When asked about whether and how certain communities are selected for sustainability projects they stated,

Pretty much the whole community can be involved with most of our projects, unless they are specific to a neighbourhood such as the "Donovan Active Neighbourhood Vision". We open many of our projects up to the public and don't really recognize if certain geographic areas are more represented then others, which is something we could work on in the future.

This insight does show that there are some geographic-based projects within Sudbury, however they tend to put on projects for the whole city versus some communities or groups.

The limited number of community focused initiatives within the York Region plan was also partially explained during the interview with York Region's Professional Planner. When asked about how certain areas or communities get picked for sustainability projects they stated:

The action plan doesn't get into specifics or neighbourhoods, and that would be something that is kind of more program level as opposed to the strategy level. So, the strategy would say we want to support full mix range of housing, but it wouldn't say we need more affordable housing in XYZ community there would be other work that does that

A large majority of the community-based initiatives outlined within all six of the ICSPs are very general in that they do not specify where or which communities are being specifically targeted. A lack of specificity in terms of who is being targeted may decrease the chances of initiatives generating benefits in an equitable fashion. Examples of this ambiguity could be found across all six plans. For example, within Ajax's ICSP it states that through development and redevelopment initiatives it can help encourage positive change in neighbourhoods and grow a strong sense of community. Similarly, Sudbury's sustainability plan states that it wants to “initiate neighbourhood-based community projects" (EarthCare Sudbury 2010), and Markham's 
ICSP states they have a goal to "reduce violence and property crimes in our neighbourhoods"

(Markham ICSP 2011). Yet none of the plans really identify which neighbourhoods or communities and why.

In addition to the need for having specific initiatives, there is also a need for implementation strategies to be considered and outlined within the sustainability plans. If the plans do not include detail on how they will be implementing identified initiatives that takes away from their overall strength and ranking.

\section{Implementation of Community Focused Initiatives theme}

Almost all the plans have at least some community-based initiatives accompanied by implementation strategies. Yet unfortunately, the majority of projects/initiatives listed within the sustainability plans are vague and do not provide many details on implementation strategies.

As stated before, the City of Markham's ICSP, is an exception in that they set out implementation strategies for every objective that has been created. For example, one of the goals expressed in the Markham ICSP places emphasis on: "regenerating existing neighbourhoods through sensitive evolution". The plan then goes on to provide initial recommendations of actions that the municipality, organizations and businesses, and communities can all take to work towards achieving this goal. For instance, for this objective they state that the municipality can,

use a place-based approach to regenerate existing neighbourhoods, focusing on walkable distances and friendly pedestrian environments from homes to shops and services, access to transit, gradual increases in residential density, mixed-use areas in neighbourhood centres and along main streets and adequate employment opportunities in each neighbourhood. Markham can also focus on sensitive neighbourhood redevelopment and "place making" to define neighbourhood units within the larger community, responding to socio-cultural aspects of neighbourhoods, architectural character guidelines and public engagement needs. In addition, regeneration of neighbourhoods should include water and 
energy efficiency retrofits to improve conservation and opportunities to reclaim materials to assist with materials management. (Markham Greenprint 2011)

This is a good example of Markham providing detail into how specific goals will be implemented through specific actions. However, they do not go into detail on who will be leading the various actions, the proposed timeline and cost etc. Nevertheless, this is a strong example of implementation strategies in comparison with some of the other ICSPs, that merely stated their objective without outlining how they would go about achieving that goal.

Frontenac County provide detail on specific actions they will be taking. For instance, they have an initiative where they want to create a network of multi-purpose cultural and recreation facilities that would accommodate a variety of users. This initiative has a detailed implementation strategy where it is explained what role the County should have in implementing these cultural centers, what potential partnerships they want to pursue, in addition to identifying site locations and facility usage.

York Region, and the City of Kingston's Sustainability Plans do not adopt the practice of stating an overall objective followed by implementation methods, roles and responsibilities for various groups as was customary in the other plans. Sudbury's sustainability plan outlines who is leading different initiatives and what partners can do to help implement the initiatives to some extent but overall this is very vague and brief. Thus, the City of Kingston is similar. For example, Kingston has the objective to "attract and retain new migrants/immigrants to further grow Kingston's population and develop their labour market and cultural diversity (Sustainable Kingston 2010). However, they provide no information on how this will be completed, or what will be set in place to make sure that this goal will be achieved. 
To be fair, the Kingston plan has a section on implementation within the introduction of its plan. They break down implementation into five points with emphasis on the:

- Creation of a community-based Sustainable Kingston Organization and an associated governance structure

- Raising awareness of community sustainability and the Sustainable Kingston Plan

- Soliciting participation in the Sustainable Kingston Plan from partner organizations and from individual citizens

- Publishing of an annual community sustainability report (or State of Sustainability Report) including the indicators contained within the Sustainable Kingston Plan

- Organizing and hosting an annual or bi-annual community sustainability conference

However, Kingston's overarching comments on implementation does not replace the need for individual initiatives/projects to have implementation strategies associated with them. a

York Region's sustainability plan has very sparse implementation strategies within its community focused initiatives. An example of this is their intent to "coordinate with the agricultural community to promote local agriculture to local markets, retailers, restaurants and other related business" (York Region Strategic Sustainability Plan 2007). They did have some projects where they outline the need to research specific information to help inform better policy but they do not detail much implementation beyond that.

\section{Summary of Results}

Overall for the community focused theme, all 6 ICSP were quite weak. Even in cases where there is a strong level of detail on what actions are needed to be executed, there was still a lack of clarity around how and when implementation would happen. Markham, Kingston, and Ajax all had strong specificity around community focused initiatives, however they did not have strong implementation strategies for their initiatives. 


\subsubsection{Consideration for Marginalized Populations}

The theme Consideration for Marginalized Populations is very similar to the theme Community Focused Projects, but it refers specifically to initiatives that are focused on vulnerable/disenfranchised communities and individuals. Considering this factor helps in identifying which plans actively pursue and prioritize equity within their initiatives/projects. For this thesis and theme Marginalized Individuals and Community is defined as individuals or groups whom may be at greater risk of disadvantage or social exclusion through social and economic structures. This includes but is not limited to low -income individuals, racialized individuals, new immigrants, people with disabilities, etc. (Parker \& Crabtree 2018).

The City of Markham, Kingston and the Town of Ajax both received a ranking of 4 for their level of attention given to marginalized populations. Whereas the City of Sudbury received a ranking of 1 for they had little to no presence of initiatives focused on marginalized populations.

\section{Specificity of Consideration of Marginalized Populations theme}

Unlike what was observed within the theme community focused initiatives, there was not as large a spectrum for different levels of specificity within articulated goals that considered marginalized populations. However, there are some exceptions where initiatives are expressed as having the intention to create greater social equity for all, with no specific marginalized population identified explicitly. When considering rankings for this theme the quantity of initiatives that are specifically addressing considerations of marginalized populations hold a lot more weight (than previous ranking of themes) because there is not a wide array of specificity within this theme.

As stated above Kingston, Ajax and Markham 'consider marginalized populations' clearly in their plans with many actions/ initiatives specifically focusing on marginalized populations. 
The Markham sustainability plan has created many initiatives specifically around poverty reduction and reducing homelessness within the city. For instance, they have stated that they want to "work with York Region, developers, builders, and other community partners to increase the supply of subsidized and social housing; and alternative forms of affordable housing models such as rent-to-own, and home ownership cooperatives" (Markham ICSP, 2011). They further outline affordable housing and poverty reduction initiatives throughout the plan. For example, they discuss their desire to:

- Adopt strategies to promote rental accommodation in new and existing housing developments and provide incentives and innovative funding methods to help Markham meet its affordable housing and special needs targets.

- Make full use of policy and regulatory tools and pursue partnerships and government funding to deliver housing tenure diversity, and non-market affordable and supportive housing options in large-scale redevelopment

- Build on work with partners to create employment opportunities for unemployed, underemployed and low-income individuals who reside in Markham, including youth and the diverse populations

- Partner with others to support affordable and accessible childcare throughout the community

(Markham ICSP, 2011)

As well Markham has initiatives and goals that address both mental and physical health of their residents and educational barriers within their community. For example, they state they want to “develop and deliver healthy eating and lifestyle curriculum and provide programs for those with mental health issues with Markham libraries, Community Centres and school boards" (pg.137).

Further insight into the consideration of equity within the ICSP was gathered from the interview with Markham's Sustainability Manager. When asked about the prioritization of equity within their sustainability plan they stated,

Okay I wouldn't say that it is a priority and the reason is because whatever project we are doing of course make sense for our community, maybe the answer is yes, but we don't say this neighbourhood is lower income over that neighbourhood so we need to focus on 
this neighbourhood, we do try to prioritize our programs city wide so everyone can benefit from it...

I think we do try to focus city wide; we don't particularly choose a neighbourhood because it is lower income or a lot of newcomers, that is not how we think, we do try to make it equitable for everyone to participate regardless of income.

The City of Kingston's sustainability plan puts a strong emphasis on social equity and vulnerable populations. Within the Kingston sustainability plan one of their core themes is diversity. Under this theme they provide examples of some of their social equity goals that specifically address marginalized populations. These include:

- fostering awareness and understanding about people of differing races, ethnicities, cultural backgrounds socioeconomic status, sexual orientations, genders, physical disabilities and/or religions.

- Providing people of diverse backgrounds with opportunities to know, understand, and appreciate each other.

- Supporting and nurturing organizations that develop capacity, empower, and provide a network for racial, ethnic, cultural, socioeconomic, gender, sexual, physical, and/or religious groups, and

- Developing indicators that measure quality of relationships, understanding, or acceptance between groups" (Kingston)

Moreover, Kingston also acknowledges their Indigenous history, culture and land within the plan. For example, it states that they want to "build local identity through increased public awareness and appreciation of Kingston's non-tangible heritage assets represented in indigenous knowledge, shared experiences, oral history, traditional practices and skills, and local sense of place" (Kingston 2010). Also, Kingston has many other initiatives addressing poverty reduction, homelessness, and equitable employment.

When interviewing The City of Kingston's Environmental Director, they acknowledged that the small integration and acknowledgement of Indigenous history and culture was a good start but not nearly enough. They explained that if the ICSP were to be redone today there would 
be a much larger integration of Indigenous voices and ideas.

Well one of the things I would say is when we did our ICSP we did not have a large Indigenous component to it, and since the production of the ICSP it has become much more important to the municipality and many community organizations to have inclusion of aboriginal interests. I think that if we were going to update the plan, there definitely needs to be seat at the table for our Indigenous community here, to make sure they have a voice because their recognition of their history and culture is important.

As well when asked if there was a prioritization of equity within the sustainability plan the City of Kingston's Environmental Director stated that “No, I don't think they were prioritized I think they were given equal weight across the 4 pillars"

Further explaining,

Yes, that was a major theme of the sustainable Kingston plan, was the integration of the pillars, so it is one thing to have an initiative and project that focuses in on economic sustainability, but it is a better thing if it also includes integration of social cultural or environmental aspects, so the equity issues resides within the social pillar, the premise of the plan was that all those things should be integrated together within decision making as best they can"

When later asked what the barriers to prioritizing equity within sustainability plans were they stated,

I don't think there were any structural barriers, but I think maybe from social perspective getting certain groups of people out to events and share their voices is difficult, there are certain groups of people disadvantage people in the community that it is hard to communicate with, making them aware of such then and getting them to participate is a structural difficulty. But in terms of implementing of all these things, I think the greatest barrier is peoples time and money, doing projects and so forth, you need time and money to do it and there is only so much ion that to go around.

The Town of Ajax has created initiatives that focus on populations that none of the other sustainability plans addressed. For example, they have education/school-based goals for youth, including the desire to:

- Improve special needs education and programs 
- Continue anti-bullying initiatives

- Continue and expand programs that promote positive mental health in schools

- Continue substance abuse awareness programs in high schools in partnership with police departments

(Ajax 2012)

Ajax also has a number of project recommendations that are specifically focused on promoting elderly health and well-being, affordable housing, education programs, and mental health programs.

York Region received an overall ranking of 3 for their attention given to marginalized populations, due to the fact that their plan exhibited a moderate level of attention to specificity and implementation, in addition to a moderate number of initiatives that are focused on marginalized populations and communities (see Table 4), in comparison with Ajax, Markham and Kingston. These latter communities received a rank of 4 . The York region plan addresses transportation accessibility for vulnerable populations. These excerpts provide two illustrative examples:

- Ensure that all residents and employees, including new immigrants, the elderly, young people and the disabled have barrier-free, accessible and affordable transportation

- Create new communities that prioritize mobility and access so that everyone is entitled to reasonable access to all places, goods and services in the Region. This includes people with physical disabilities, low incomes and the elderly.

(York Region Strategic Sustainability Plan 2007)

The York Region sustainability plan also has a moderate amount of initiatives that pertain to poverty reduction and affordable housing. These include updating their affordable housing strategy, working with private sector and public agencies to provide housing choices for all, and working with the province and municipalities to promote "secondary suites" across York Region 
to help housing choices and affordability. When asked about whether they think equity principals were prioritized in the sustainability plan a Professional Planner from York Region stated,

It wasn't explicitly addressed in the plan, but I do see equity principles throughout the actions identified in the plan [...] With the sustainability strategy, as opposed to taking action to improve equity, improvement of equity was kind of a result of the action

Frontenac County received an overall ranking of 2. It has only three different initiatives that are focused on marginalized populations (Table 6) and all three of these initiatives are not described in any great detail. There are initiatives that are created for the aid of marginalized people; however, Frontenac County does not specify which marginalized populations, or acknowledge social equity within them. The first initiative involves addressing homelessness and housing concerns, building off of recommendations outlined in a study focused on this issue that was conducted by the municipality in 2007 . The second initiative is to 'Review the Need for Long Term Care'. This initiative aims to address the supply and demand for long-term care, to help enable community members to stay in the County. Lastly the third initiative is to 'Act on Recommendations of Frontenac Transportation Collaborative', this initiative was created to start implementing projects that were highlighted within the Frontenac Transportation Collaborative Plan (created prior). The Act on Recommendations of Frontenac Transportation Collaborative initiative states that its goal is the implementation of "better coordinated transportation services for residents who cannot otherwise travel for medical appointments, recreation, educational/social programs, employment training and shopping for necessities" (Frontenac County 2009). Clearly, they are acknowledging the need to aid vulnerable communities however they do not go into specifications of which populations are at risk of these issues. 
The limited prioritization of marginalized populations can be partially explained when the interviewing the Director of Planning and Economic Development for Frontenac County. When asked about the prioritization of equity within the formation and implementation of the ICSP, they stated,

when I think of equity planning, I think of advocacy planning, and that is making sure everyone in the community is thought about while making these decisions. My sense is that was not happening. I don't think anyone was speaking for the poor people in Frontenac, that is still a challenge to this day, it is a challenge in any jurisdiction, but it can be done, and I think the efforts we have made in trying to promote affordable housing

When further asked about what they thought the main challenges and barriers to equity prioritization were the same respondent stated

It is political, and again in rural Ontario, many townships not just the ones here, have very little financial ability to make choices, unlike cities that can make major capital investments. Two out of 4 townships have barely any money in their reserved fund, so equity issues are not on their radar. That is why I think it is a regional issue to put it on their radar

The City of Sudbury's plan does not have any initiatives/projects that are focused on marginalized populations; therefore, they received a ranking of 1 because they gave little to no consideration for marginalized populations. Having said this, when interviewing Sudbury's Sustainability Program Coordinator, they highlighted the ways in which they work with Indigenous populations,

We do engage with our local Indigenous populations but there could definitely be better communication. For our division, environmental planning, we work with representatives from our two First Nations on various projects such as tree planting for our regreening program and plant surveys for our biodiversity program. We also have public events where we can provide a tipi for our Indigenous partners to use to share their traditional knowledge, specifically about water during our annual Water Festival. We hope to build a good working relationship so that there can be open discussions over barriers and frustrations in current or future sustainability projects. 
When asked about whether they thought that equity principals are prioritized within their planning process for their sustainability plan, they stated,

I know most staff consider it when we work on plans like this. I can't say if it is a priority for all plans, but it is a consideration. Organizations that work on equity, such as the Social Planning Council of Sudbury, were original partners during the development of this sustainability plan.

When asked about whether not prioritizing equity is a conscious decision within the creation and the implementation of the plan, they stated,

Because I wasn't there at the planning, I can only speak for the implementation. I almost feel like it is just common practice now when we are sitting down discussing projects. We have certain neighbourhoods, for example, and we often ask questions such as "How can that neighbourhood be involved?" or "How will residents in that neighbourhood feel about this?" We recognize certain regional sensitivities and abilities, so we want to make sure the project addresses their concerns and is accessible to everyone.

These insights that were gained through the interviews indicate that while attention to marginalized populations was not explicitly outlined in the ICSP itself, during the implementation phase there was some effort made to consider the needs of marginalized populations.

\section{Implementation Strategies for Consideration of Marginalized Populations theme}

As stated above there is not a wide range of difference with respect to the degree of specificity given to initiatives targeting marginalized sub-populations. In contrast, when it comes to implementation strategies, there is a significant difference across plans with respect to the amount of attention given to outlining implementation strategies.

The City of Markham has a few strong implementation strategies for their initiatives that focus on marginalized communities. Nonetheless even though they describe some 
implementation strategies they still omit details of timelines, cost and the specifics of how they will get their desired actions done. An example of one of their stronger implementation strategies is their objective to reduce the impact of household poverty. For this objective they list out their implementation recommendations including for the municipality to,

work with regional and senior governments to facilitate an affordable housing and transportation strategy and proactively design a range of housing and transportation options that can be accessed by all. Markham can offer geared-to-income options for its full range of programs and services and promote a welcoming, accessible and inclusive environment in all municipal facilities, parks and public spaces.... Markham can also enhance its social planning capacity by integrating social activities and services not currently being delivered. (Markham ICSP, 2011, pg. 28)

Kingston has many highly specific initiatives that are focused on marginalized populations, yet the plan has some ambiguity when it comes to implementation strategies. In comparison to Markham's poverty reduction and affordable housing initiatives that state specific policy strategies and potential collaboration efforts, Kingston just states that they want to "ensure a range of affordable and efficient housing choices with varying levels of care[...] support the inclusion of affordable housing in new developments"(Sustainable Kingston, 2010). The inclusion of these benefit Kingston's overall ranking because it is good that they are highlighting the need for affordable housing and poverty reduction, but the ambiguity of related implementation strategies also needs to be recognized.

The Town of Ajax has sparse details on implementation strategies for initiatives that are focused on marginalized people. For instance, one of their potential actions is to "encourage the development of affordable housing taking into consideration cultural diversity, seniors, youth, and disabilities" (pg.65), yet there is no detail given on how they could go about doing this. An example of one of their initiatives that has a bit of a stronger implementation strategy is their 
goal to "develop an Older Adult Strategy to assess the service and program needs of seniors" (pg.68). This action item provides a clearer implementation process, yet it could be improved by giving more detail on timelines and how this strategy will be created. direction.

When considering specificity York Region has a moderate amount of initiatives that consider marginalized people, yet they do not have many detailed implementation strategies outlining how they will achieve these initiatives within their ICSP. For instance they have one initiative that states they want to “design new communities in the Region's Whitebelt which considers the social determinants of health to help the community and individual realize their full potential with respect to health, social equity, culture, environment, economic vitality and sense of place" (pg. 13). Whitebelt is the area between the urban development areas and greenbelt areas that can be affected differently in growth plans (Neptis, 2013). There are no further details in this plan on how this action item would be achieved. They have some initiatives within their plan that are more about changing policies that have some semblance of an implementation strategy because they highlight which policies or plans, they will use or create to achieve their goal. An example of this is their goal to "work with partners through the Inclusivity Action Plan to ensure that the potential of all new Canadians is realized" (pg. 14).

Frontenac County does not have many initiatives within their ICSP that specifically focus on marginalized populations, however for the couple of initiatives they do have they have embedded some implementation strategies. Within their initiative "to act on their Homelessness and Housing Study Recommendations' they state that the "Consolidated Municipal Services Manager [in City of Kingston] should undertake and complete a housing study for the County" (Frontenac County, 2009, pg. 7). The study includes a detailed inventory, assessment and set of recommendations to assess the current housing stock (location, types, prices, and services), 
housing needs, and the opportunities for development. They give detail on the type of study they want to be completed, and outline which partners they will be conducting it with.

\section{Summary of Results}

Overall the theme Considerations for Marginalized Populations, was a low performing theme. There was not a large spectrum of specificity within the plans in regard to this theme, there was either initiatives that directly considered marginalized populations or there was none. Unlike other themes where they there was a lot more variety of specificity and vagueness. Markham and Ajax preform the strongest in that they have the most amount of initiatives and goals that specifically consider marginalized populations, however Ajax's plan was sparse on the details of how they implement their goals, even though their ICSP format aid in giving overall implementation methods. Sudbury preformed the weakest by having zero goals or initiatives that focused on marginalized populations. The interviews highlighted some key insights that were not forthcoming in the ICSPs. One key insight and similarity across all the interviews was that in discussion prioritization of social equity, all participants stated that social equity was not explicitly prioritized within the plans or implementation, it was more of inherent understanding that social equity needed to be done. This notion of 'inherent understanding/demonstration of social equity' can lead to shortcomings in actually addressing and achieving social equity, which is discussed further in Chapter 5. Discussion \& Conclusion.

\subsubsection{Measurement Indicators Based on Aggregate Population \& Scale versus Indicators}

\section{Based on Community and/or Population}

This theme is an analysis of the different measurement indicators each plan uses. It is specifically looking at whether the ICSPs use aggregate population scale indicators or 
community/population-based ones. As explained by Pearsall and Pierce in their study (2010) indicators that conduct measurements on a city-wide or aggregate scale cannot be considered to have distributional equity elements to it because this scale of measurement does not give people a true representation of what is actually happening on an individual or community level in the city. An example that these authors use is the "percentage of people over the age of 25 with at least two years of specialized education after high school". On the surface, this measure seems to be looking at baseline education rates across that specific city, however it does not consider whether certain communities or populations are systematically privileged, marginalized or excluded from obtaining this educational objective (pg.577).

For the most part all the sustainability plans, aside from Sudbury and York Region, have indicators that they are using to monitor and track their performance in all the different areas of their sustainability plans. All of the other four municipalities/regions have different indicators for each pillar of their sustainability plan. The City of Kingston and Frontenac County list all the indicators used in their appendix. The Town of Ajax and The City of Markham included their indicators within each chapter's section (i.e. environmental, social, economic, cultural and any additional that are specific to the plan). York Region and the City of Sudbury still have some indicators scattered throughout their plan; however, they do not have any consistency for measurement indicators like the other plans.

All of the plans use an abundance of indicators that measure at the aggregate population level. For example, there are a few different ICSPs (Markham, Ajax, Kingston), that measure of the number of greenspace/trees within a municipality. Yet little attention is given to where this greenspace is located within the city geographically or whether it is accessible to different populations. 
Overall, the City of Markham has the most indicators that are measured at a community or population level. Yet, this is for only 6 of their 49 total indicators (with the remaining 43 being measured at the aggregate level). An example of one of Markham's aggregate indicators is 'The Talent Index' which measures the percentage of the population with a university certificate, diploma or degree (or higher). Whereas the Bohemian Index compares the percentage of "bohemians" in a region to the national pattern; it shows the concentration of writers, designers, musicians actors and other arts-related personnel and is a comparative measure of an areas cultural amenities (pg.79) versus the aggregate scale of just measuring the unemployment rate. The indicator measuring both the Talent Index and Bohemian Index give a much more equitable understanding of the community than just looking at the unemployment index, for the unemployment index may not consider students in school, freelance artists and others within its measurement. The City of Kingston has a total of 42 indicators, with only 4 being based on a community or population. An example of a community or population-based indicator is their use of the "Composite Learning Index [which] is an annual measure of Canada's progress in lifelong learning. It is based on statistical indicators that reflect the many ways that Canadians learn, whether in school, in the home, at work or within the community" (pg.59). The use of this is more equitable than for instance the use of an aggregate educational indicator that just looks at the population with certain school degrees. Frontenac County has a total of 46 indicators with only 4 being based on a community and/or population. Lastly the Town of Ajax has a total of 47 indicators with only 2 being based on a specific community and/or population. An example from the Town of Ajax is participation in Ajax' educational opportunities by type, (as a percentage of total population). Both Sudbury and York Region do not share any measurement indicators within their sustainability plan. 


\section{Summary of Results}

This section looks at the types of measurement indicators that were used within the six different ICSPs, specifically focusing on whether there were more indicators that measured based on aggregate population or community/geographic focused ones. The reason behind looking at the different indicators is based on Pearsall \& Pierce(2010) theory that aggregate indicators do not show correct measurements of equity or quality of life. For all six of the plans, they all had very few indicators that measured on a community/geographical basis and a majority of their indicators were based on aggregate population.

\subsubsection{Distributional Equity Conclusion}

Distributional equity within the environmental justice framework refers to the distribution of environmental harms, burdens, services, projects etc. (Scholsberg, 2007; Pearsall \& Pierce, 2010; Teelucksingh \& Masuda, 2014). Distributional equity was one of the codes used for the document analysis of the six ICSPs, under distributional equity was 4 sub-themes, community based initiatives, consideration for marginalized populations, indicator measurements based on aggregate, and indicator measurements based on community/geographic, the latter two being put into one section. For the most part, the ICSPs ranked fairly poorly within distributional equity compared to the procedural equity themes. Across all six ICSPs there were few initiatives that focused on marginalized communities and populations. Yet, of the initiatives that were identified as focusing on a specific marginalised community, many were quite weak when it came to implementation. The City of Markham and the Town of Ajax, both ranked the highest for both community focused initiatives, and focus on marginalized populations, where Sudbury's ICSP ranked the lowest for both. Moreover, all 6 of the plans had a very low amount of indicators 
measurements based on community/populations. Thus, showing that for the distributional equity sub-themes all the plans did relatively poorly compared to the procedural equity sub-themes.

\subsection{Broader Insights on the Governance \& Conceptualizations of ICSPs}

Aside from municipal and regional employees, interviews were conducted with two ICSP experts and researchers in order to gain further insight and context into the ICSP program. An interview was conducted with a Green Municipal Fund (GMF) employee at The Federation of Canadian Municipalities, in June 2019, who oversaw the ICSP applications and funding for the GMF, which funded ICSPs. This interview was focused on background information on the ICSP, and the role both the federal government and the Federation of the Canadian Municipalities played in funding and supporting the ICSP program. When asked about the role the FCM played in the ICSP program and funding, they explain that the GMF is an endowment fund managed by the FCM, and there was a category of eligible funding for sustainable community plans. They further explained that "the way [the] GMF helped shape those was really in the questions we asked in the application form to evaluate whether the project/ initiative would result in good outcomes that would align with our program objective".

Specifics of what was in the funding criteria could not be shared during the interview, however it was reconfirmed that the ICSPs did use the triple bottom line approach to sustainability, but also had a focus on municipal infrastructure projects. When asked if there was funding for more social or cultural sustainability focused plans instead of a focus on infrastructure they stated,

I think there was flexibility within the funding application to put a stronger focus on the social aspect if that was important to the community, but I don't think it was something we necessarily required or encouraged directly... There was also a component, that I also 
recall was important to highlight was the community engagement piece in the development of the plan. But in terms of building social infrastructure or enhancing social/cultural element I don't recall that being a focus

Moving on to talk more specifically about public engagement, when asked if there was any guidance or support from the FCM or federal government in terms of best practices for public engagement they stated,

I think that is a perpetual question, I think those resources are still needed. I've been in conversations and workshops where municipalities are still grappling with how to do effective public engagement, and kind of break out of the model of having an open house at the time of day that no one can attend. I can't think of any specific resources that were developed in conjunction with the funding application for SCP.

When asked whether the FCM had any guidance available for municipalities or regions to address and/or commit to equity principals within their ICSPs they indicated that they did not. This interview was informative for background insight of the ICSP program, it helped clarify and reconfirm some of the information that was in the background and context documents for the ICSP. Moreover, it highlighted the emphasis of infrastructure within the ICSP program and funding, and the lack of prioritization of social sustainability. Further there seems to be a lack of documents and resources given to municipalities and regions that wanted to create an ICSP. When interviewing the different municipalities none of them could recall receiving any sort of supporting documents or guidance from the FCM or federal government to do with either addressing/ prioritizing equity or community engagement.

Another interview conducted was with an independent professional ICSP researcher. This researcher has done their PhD conducting original research that was an analysis of ICSPs in Canada with parts of their research touching on equity and community participation frameworks. The interview was completed May 2019. The interview gave a lot of insight on the background 
and more specifically equity within ICSPs. When asked about the background of how ICSPs

came to be and why an integrated sustainability plan was the model chosen for municipalities to

work with, they stated,

I think it is because there was a recognition of system planning that you cannot plan with new infrastructure or fix old infrastructure anymore without thinking of other systems and community and so there is recognition now infrastructure is connected to human health, it is connected to accessibility, and in that way it is connected to equity, it is connected to environment and impacts to the environment, greenhouse gas emissions and so on. And that is why I think this integrated lens was provided, and integrated community sustainability planning phenomena took off, because there is many communities a ground swell and great grassroots interest in sustainability and that is why a lot of the ICSPs were infrastructure focus, [and] were more dreamy in terms how they wanted their communities to look.

In response to the questions about who or which organizations/actors typically were involved in the creation of the ICSP they stated that in all of the ICSPs they looked at in their research they were led by municipalities. However, they noted that the reason it is not community or grassroots led is because of the funding, because the objective of the funding was for the infrastructure deficit that municipalities were facing. ICSPs were then only really created or led by municipal governments, but it was noted that a lot of grassroots and community organizations would get involved once the municipality started the process or gained the funding. Following up this discussion, the question was asked if the focus on infrastructure weakens the opportunity to have social equity or cultural sustainability dimensions within the ICSP, they stated

It absolutely did because a lot of the plans I looked at were really related to things like let's fix our arena, let's build a new community centre, lets fix the brigade over here, let's make access to this fishing port easier for fisherman in our community. So, in some ways social equity is part of all of that but it wasn't explicit it wasn't at the forefront of planning" 
When asked within their research how they saw the public was involved in shaping the creation of ICSPs they stated,

Methods reflected more or less restrictive [as opposed to] open ended approaches to including the public, and also, I found that the actual processes were weak opposed to strong in the sense that the input that the [community] members had that was it.... They had one chance, an opening to participate in the visioning phase, and somewhat in the plan formulation phase, but were not considered as truly collaborative as people were collaborating with them, they were not involved in the implementation of the plan or made accountable to implementing it all

They further explained that with restrictive approaches to public engagement municipalities would not allow people to make up their own answers, using techniques like multiple choice, or voting on specific ideas as opposed to communities choosing their own options and providing their own feedback, which in their opinion is a much more collaborative method. They did note that there were some exceptions, specifically noting that Kingston's creation of a sustainability office that was community owned and operated was a good way for the municipality to recognize the importance of and try to give community ownership. Yet they did go on to say that it does not mean that the organization is working perfectly without its own challenges.

While speaking on how a municipality can go about changing their community engagement strategies to make sure it is more inclusive and not just the same people all the time, they stated,

There is a capacity issue, a communication issue, and then I think more broadly then that there is just not a lot of interest, more generally in the public. It's a cultural problem. I think that generally in communities you have a pocket of engaged people that become engaged for specific reasons like economic ones, or moral ones, or multiple reasons, or ones whose family is always engaged. But then beyond that it is just that a lot of people are not really interested in participating in local governments. It is a question how you reach beyond the usual suspects... a methods question, but also how do you get people interested beyond just the usual suspects - that is a huge big marketing question. 
When asked whether they thought equity principals were prioritized within the planning process of ICSPs they argued there were a lot of concerns from communities within the plans, which could be interpreted as paying attention to equity issues in a very implicit way, or without using equity terminology. For example, instead of a community talking about equity explicitly, they were thinking about things like loss of local knowledge, loss of low-tech skills, need for local goods. In summary they stated,

I could see that many of them were equity concerns, but they were not coming from an explicit equity place. There were more coming from a concern of I want to have more fun on the weekend, I want my community to have more services available to me

When commenting on barriers to prioritizing equity within sustainability planning and specifically these ICSPs, they said,

I think there is a lack of incentives to do that from provincial, federal levels. There may be lack of knowledge of the planner on how to do that in sustainability planning. And maybe a lack of habit and maybe just out of habit equity concerns are not top of mind. You know I wish I could speak to more generic patterns now, because I think equity is generally a concern in urban planning but it is more in terms of accessibility to the bus and how often it runs, It is not a deep concern for the disruption of goods and services opportunities, freedoms and rights. In the community I think that is hard core what equity is. And I think because urban planning is all about the built environment and how we do that it can be difficult for planners to understand how the built environment influences the distribution of goods, services, rights, freedoms and opportunity. I think there is a conceptual level problem, planning practice doesn't know or think about it much.

This interview gave a lot of insight on the theoretical planning perspectives that went into the ICSPs program. It helped with understanding the different practices in public engagement strategies as well as prioritizing and addressing equity. It gave further insights that help create a clearer understanding of what were prioritized within the creation and implementation of ICSPs for different sectors and the reasoning behind some of the gaps in social equity sustainability. 
In discussing governance models and their effect on ICSPs and addressing equity, there are two separate topics that need to be expanded upon. First is the breakdown of the different types of municipal governments (two tier, single tier) and the barriers that the different types may face. Second, is how different governance models, (e.g. government led, or community led) and how they influence how equity is addressed within sustainability plans.

Firstly, within the six plans analysed for this study there are three separate types of municipal governments that were looked at, an upper tier (regional), lower tier and single tier governments (Government of Ontario, 2019). Both Frontenac County and York are upper tier municipal governments, meaning they are a central regional government that governs over multiple smaller townships. Markham and Ajax are lower tier municipalities, because they are both also located within an upper tier government, and Kingston and Sudbury are single tier municipalities.

During interviews with employees in both Frontenac County and York Region, they were both asked about whether they think there are unique barriers that upper tier (regional) governments face in creating and implementing sustainability plans, and if yes what they were. Both participants stated that there were barriers they faced, yet they each described different barriers. When interviewing the Director of Planning and Economic Development of Frontenac County they answered that,

The one barrier we face is cooperation and buy in. Municipalities if they choose to pursue a sustainability plan, that is a local decision and once they made the decision, they start to work on it. And the expectation is eventually a document they create will be approved by the municipality. That is not the case for the regional level. There were especially Township staff and some Township politicians [that] wanted nothing to do with what Frontenac was doing period $[\ldots]$ how to stop the county from getting more staff, how do we keep the county out of our business. 
Meaning that when regional governments do try to enforce regional plans, like a sustainability plan, there can be push back from townships due to fear of losing political autonomy and representation within a broader regional government.

When asked the same questions, the planner from York Region answered that "one of the main differences is scale. There are things we address that the local municipalities don't, or the local sustainability strategy might look at some different components or elements", they went on to explain that their actions are higher level and less specific than what would be at a local level as a result of a local municipalities having closer interactions with residents on a regular basis. In other words, this key informant believed that sustainability plans created at the local municipal level can be much more specific with their actions and projects. Both barriers described by the interview participants highlight the difficulties that regions face when trying to create and implement a sustainability plan.

The second aspect of governance that will be addressed is the types of governance model used to create and implement the sustainability plan. For the majority of the ICSP, analyzed within this thesis, the governance methods were quite similar. The majority of the ICSPs were created and implemented in a very government -led (top-down) method. All six of the ICSPs were created in house by their respective municipal governments, with various amounts of community participation involved in the process. The City of Markham, City of Sudbury, Town of Ajax, and York Region, all prescribed to a government led method of creating and implementing their plan. Their ICSPs were created in house at the municipal/regions office and implemented by the municipality and region. There was variance in the level of community participation within these four examples, as can be seen in sections 5.2.2.2 and 5.2.2.3, but that does not take away from the fact that they are government led plans. On the opposite side of the 
spectrum Kingston was the only sustainability plan analyzed that tried to adhere to a community led (bottom-up) governance model. Their initial ICSP was created through a municipal steering committee involving community input, however their sustainability plan was then housed in an arm's length sustainability corporation, for the purposes of putting control over the implementation of the sustainability plans into the hands of the community (in partnership with government).

The City of Kingston's governance method for implementing their ICSP has the capability of achieving a successful an equitable implementation of their sustainability plan; as explained in Chapter 2. literature Review under S. 2.3.1 that community led sustainability plans have the ability of equitable distribution of power. Though this does not inherently mean that Kingston's method is the best and is working perfectly. When interviewing the Environmental Director for the City of Kingston, they explained that the Sustainable Kingston office "has now moved away from focusing on just implementing the plan, they now do other community sustainability projects, but they are still guided by the plan". Additionally, the Community Engagement Specialist at Sustainable Kingston Corporation stated that they have "created [their] own six priority areas that work in conjunction with that plan [Kingston ICSP], and that is what [they] base [their] activities on". The deviation from the plan could mean that there is not much strength in Kingston's ICSP, if its goals and projects are not being followed then there is very little point to public engagement and participation that was used to create the ICSP.

The independent researcher on ICSPs, whose expertise was not tied to any one single community or study site also offered insights into which governance model that felt was better suited for advancing equity goals: 
The thing that comes to mind right away is just the distribution of power in a community can really effect whether or not equity is a priority and the best way to cut to the heart of the distribution of power is truly collaborative planning. That is really tough and does not happen very often. [There are] examples of participatory budgeting in New York, and other places in South America where communities get together and they literally decide together what they want to spend their community budget on.

\subsection{Chapter Conclusion}

The results found throughout the document analysis and semi - structured interviews show that there were some attempts of consideration and addressing social equity and social sustainability concerns within the ICSPs. Yet, it is quite evident that there are large gaps in strongly considering equity and social sustainability throughout the ICSPs. Additionally, the different governance models of the Ontario ICSPs were highlighted showing the barriers each governance model faces. These results will be further discussed and analysed in the next Chapter. 


\section{CHAPTER 5: DISCUSSION \& CONCLUSION}

\subsection{Discussion}

This chapter provides a discussion and conclusion of the key results found throughout this research. The objective of this study was to examine how Ontario Integrated Community Sustainability Plans addressed equity principals within their design and implementation. Secondly, it sought to examine how variations in the degree of community involvement in the creation and implementation of Integrated Community Sustainability Plans influence what is prioritized and how equity is addressed. This in-depth qualitative study drew upon the thematic the concepts of procedural and distributional equity to help analyze the six ICSPs and address the research objectives.

Some of the of the major findings that arose from this research include the fact that across all of the ICSPs that were examined there was an apparent disconnect between identified policy goals and details in implementation; and a limited prioritization of equity, particularly with respect to meaningfully considering distributional equity concerns. Further there was evidence of a lack of prescriptive guidance by the federal government and FCM with respect to goals and implementation. Finally, the intention for the Gas Tax transfer to fund hard infrastructure projects may have inadvertently contributed towards the limited attention that was placed upon social sustainability and equity concerns, despite the fact that communities were required to consider social and cultural sustainability pillars within their plans. 


\subsubsection{Disconnect Between Policy Goals and Implementation Details}

A majority of the results from this study have come from a document analysis of the ICSPs. The semi-structured interviews were used to gather further insight on specific topics in the hopes of getting a more meaningful picture on inner workings of the plans. For the most part the interview data complemented the results found through the document analysis, however, there were some instances of discrepancies between what was written in the ICSPs and what was discussed during interviews, which helped provide additional behind the scenes details around the actual operation and implementation of the plans. At times there was a disconnect between what the plan stated (or not) and how things actually unfolded in implementation and practice.

A study by Markvart (2015) on the condition of sustainability planning in Canada, similarly, concluded that there appears to be a disconnect between what is stated in the ICSPs and what actually becomes implemented. As well, there is not only the issue of disconnect between policy or implementation details but also a lack of measuring and monitoring to ensure that implementation and growth is happening. Within Infrastructure Canada and The Natural Step (2011) report one of their findings was that $40 \%$ of the respondents of their survey reported that their plans did not include indicators for monitoring and evaluation, which limits the ability to measure the implementation process. As well, the Office of the Auditor General (2016) report found that Infrastructure Canada did a poor job managing, monitoring, and tracking the funds given out for the ICSP program, and could not adequately demonstrate that the fund had resulted in any improvement of sustainability, namely the 'cleaner air, cleaner water, and reduced emission of greenhouse gases' that was their baseline goal (The Office of the Auditor General, 2016). 
One major instance of this disconnect between policy and implementation is in Public engagement (5.2.2.2). Within this section the document analysis showed that York Region received a ranking of two for public engagement, whereas Sudbury also received a ranking of two. York Region had received a ranking of two for public engagement because within the plan it acknowledges that community feedback was used to help create the sustainability plan, and there was a sustainability symposium and advisory group created that was dedicated to sustainability within the region. However, compared to the other plans, it was lacking a lot of detail about the actual process.

However, when interviewing a planner from York Region, they explained that public consultation was not used to create the sustainability strategy, but rather to confirm or endorse the direction the plan is going in. This complete lack of public feedback in creating the sustainability strategy conflicts with what is written in their sustainability strategy, in which they state that their sustainability strategy is based on public input. Moreover, when speaking with a Coordinator from EarthCare Sudbury, which is the department that housed their sustainability plan, they explained that their sustainability plan was created through a partnership with many community businesses and organizations, not necessarily individual community members but many different organizations representing all three pillars of sustainability. Additionally, in the interview it was explained that their community engagement and feedback techniques for the implementation of their plan were very thorough, giving examples of going door to door to make sure engagement was comprehensive. This is a major finding because community feedback is a very important and imperative tool within sustainability planning (Infrastructure Canada and The Natural Step, 2011) and social equity (Pearsall \& Pierce, 2011). 
Another example of this disconnect between plan development and practice is within the Town of Ajax. The Ajax ICSP was very comprehensive and received a ranking of 4 for almost all the themes within procedural and distributional equity (Table $2 \&$ Table 4 ). The only theme in which they performed poorly was Indicator Measurements based on Community/Population (Table 4 \& S. 5.2.3.3). Yet, when contacting The Town of Ajax, in August 2019, there were no employees that worked within the sustainability department, or anyone who could talk about the ICSP. Historically the Town of Ajax had a sustainability employee, however at the time of the phone call there was no one working for the sustainability department. This leads to the inference that the sustainability plan cannot be properly implemented for there is no capacity within the organization to oversee the plan or its implementation. In order for an organization to be able achieve its sustainability goals it needs to have the proper capacity and organization of responsibilities (Bos \& Brown, 2013).

From these results a disconnect between what is written within the plans and what is happening in practice can be seen. This can be quite problematic because if the plans emphasize meaningful and important actions that then are not being implemented this can hinder any sort of progress towards achieving a goal of equitable sustainability. There needs to be consistency and accountability. The phenomena of disconnect between a plan or policy and actual implementation on the ground has been found in many other planning fields like environmental planning, transportation planning etc., not just within sustainability planning (Talen, 1996; Brody \& Highfield, 2005; Loh 2012). 


\subsubsection{Prioritization of Social Equity}

Another key takeaway from the result section was the lack of prioritization of social equity within the ICSPs. This finding was highlighted through the semi-structured interviews, and through the document analysis given some plans ranked quite low in some of the sub-themes regarding equity. When interviewing different municipal and regional employees that had worked with the ICSPs, mostly planners, one question that was asked of all of them was if they thought equity was prioritized within their plans, either within the process of creating the plan, implementing it, or just within the plan itself.. These findings are consistent with Grant et al's (2016) study on ICSPs in Maritimes, which found that social equity was not prioritized within ICSPs, and that there was more focus on environment and economic dimensions of sustainability.

The participant from Kingston stated that it wasn't prioritized but "given equal weight" as the rest of the sustainability pillars. This idea of social equity being given equal weight to other factors can be detrimental to social equity movements. The foundation and ideas of social equity needs to be prioritized to ensure that it is actually being achieved, social equity needs to be purposeful and substantial within policy making (Rivera \& Ward, 2018). Social equity needs not to be equal to 'economic dimensions etc.' of sustainability or any other, it needs to be actively worked on and part of all the aspects.

Participants from Markham and Sudbury, stated that equity was not explicitly prioritized within the sustainability planning, but it is always something in the back of their minds, including an underlying understanding of what the needs are of certain areas within their communities. Again, this is contentious because when it comes to equity within sustainability planning, it needs to be explicitly prioritized and addressed (Rivera \& Ward, 2018). 
The participant from York Region also stated similar ideas as the participants from Markham and Sudbury, that social equity was not explicitly prioritized within the plan, but within the implementation stage there is inherent recognition of certain populations that have specific needs. They further explained that the reason that social equity may not be specifically talked about within their strategic sustainability plan is because the plan is a strategic action plan, which purposefully did not go into specific details (i.e. about neighbourhoods, and communities), that level of detail would be something that is addressed at the program or project level, versus the strategy level. An example would be that the ICSP may have stated that they want to support full mix range housing, but they wouldn't have stated which neighbourhoods need more affordable housing, that would be done at the actual program and implementation level by the department within York's regional government that is involved with housing. Yet, what is not understood by someone just reading the ICSP is that York Region is acknowledging the importance of social equity but that is only seen in the implementation and program side of things, which is not necessarily seen by the public, as it is more of an internal process. Therefore, with York Region, and probably most other municipalities, there is a limit in the value of analyzing a policy document like the ICSPs, because there will always be a lot more information and detail going on internally that is not known by the public. This thesis tried to have a further understanding of the internal workings of the ICSP process and program through the semistructured interviews, however to have a more fuller picture many more interviews would be needed, as well as an understanding of the internal process needed to be done which is beyond the scope of this thesis and the research questions.

Findings suggest that the focus on funding hard infrastructure projects through the Gas Tax Fund on the part of the Federal Government, may have had a negative effect on plans 
putting social equity at the forefront of their plans. There was not a lot of explicit focus on equity within the plans, despite the fact that a lot of concerns raised by community stakeholders were of relevance to social equity concerns. One example given was bussing and the want for more frequent and cheaper transit fair. This concern might have just come from individuals wanting to get to the mall/work/recreational spaces more easily, however making mobility more accessible, dependable and convenient to the public is an important social equity goal as this shapes one's ability to access opportunities, services and amenities that are important to health and well-being (Boschmann \& Kwan, 2008).

\subsubsection{Lower Rankings for Distributional Equity}

Another major takeaway from the results of this study were around distributional equity.

Distributional equity is defined as the consideration of how benefits and burdens are distributed across places and people (Scholsberg, 2007; Pearsall \& Pierce, 2011; Teelucksingh \& Masuda, 2014). This differs from procedural equity in that procedural equity is looking at equity within the "rules and procedures according to which rules are made" (Scholsberg, 2007), including the accessibility of political and public decision-making systems.

For the most part all six of the sustainability plans were ranked consistently high within the procedural equity thematic category, the presence and strength of initiatives and opportunities was consistent across the plans with respect to considerations for public engagement and accessibility. This is not the case for the sub-themes under the distributional

equity category (Table 4), there is much more variance within the rankings. Sustainability plans that ranked a 4 in procedural equity categories were ranking low in distributional equity categories. These results are interesting because it is somewhat a contradiction from 'normal' 
social equity practices within sustainability planning. Historically environmental justice research and practice has paid more attention to distributional equity issues. The movement started as a resistance to the dumping of toxic waste in predominantly African- American areas (Schlosberg $\&$ Collins 2014). This started a focus on distributional equity, with the goal of equalizing the distribution of harms, benefits, goods, and services. However, over time many scholars have argued that procedural equity needs to be more carefully considered within environmental justice agendas (Scholsberg, 2007; Pearsall \& Pierce, 2011; Teelucksingh \& Masuda, 2014; Schlosberg \& Collins, 2014). Other studies that have examined treatments of equity within sustainability and climate action plans, in the United States, found there was a lot more understanding and work done that would fall into the category of distributional equity versus procedural equity (Schrock 2015), which contrasts with findings in the current study.

One reason this may be the case among Ontario ICSPs examined in this study is that one of the only requisite factors put in place by the federal government that had to be considered in order to obtain Gas Tax Funds was attention given to outlining community engagement strategies, which is an important element of procedural equity (Infrastructure Canada 2008, Ling 2009). Both provincial and federal governments stated that community participation was mandatory within the process of creating and implementing an ICSP (Prime Ministers External Advisory on Cities and Communities, 2005; AMO, 2007; Infrastructure Canada, 2008). Whereas themes of distributional equity were not as prominent within various background papers that were intended to help guide the process. The Prime Minister's External Advisory Background Paper (2005) does state that consideration of equity should be a key principle in the creation and implementation of an ICSP (pg. 20). However, during the interviews with the employees from the different municipalities, none of them had mentioned receiving or being aware of any 
documents or best practices regarding how to address social equity from the government or FCM. Within literature on sustainability planning, community participation and engagement is recognized as a key aspect of successfully achieving sustainability planning (Portney 2003, Pearsall \& Pierce, 2010; Markvart, 2015; Schrock, 2015). Even in Agenda 21, which is credited as one of the first documents that focused on municipal/community sustainability planning, the importance of having community participation in order to achieve sustainability is emphasized (United Nations Sustainable Development, 1992), whereas themes and the implementation of distributional equity within sustainability planning has been seen more in the academic discussion of sustainability planning (Pearsall \& Pierce, 2010).

This lack of distributional equity dimensions is quite evidence in S.4.2.3.3 that looked at the types of indicators that were used in the sustainability plans to measure performance and impact of the sustainability plan. The vast majority of indicators were measurements based on the aggregate city and not in on specific communities or locations. As Pearsall \& Pierce (2010) state:

Sustainability indicators that fail to monitor how changes and improvements are distributed geographically, as well as across race, class, and gender lines, also fail to adequately illuminate how social, ecological, and economic factors interact in producing unsustainable cities; they also hinder environmental justice analysis by providing information at the aggregate level only (pg.577).

It is imperative that indicator measurements used in sustainability planning do not just focus on the whole, one cannot measure any real improvements or declines in social equity if specific populations, especially vulnerable ones, are not given attention to (Pearsall \& Pierce, 2010). 


\subsubsection{Lack of Monitoring and Prescription from Government}

As mentioned earlier in Chapter 2 the ICSP requirement was created from a budget policy that transferred large amount of funds from the Federal Government to municipalities through the provinces. This budget policy was created to try and help fix the huge infrastructure deficit that municipalities were facing (Bradford, 2007; Markvart, 2015; The Office of the Auditor General, 2016). This budget policy saw the transfer of 13 billion dollars over a ten-year period, 2005-2015 (The Office of the Auditor General, 2016). However, even with such large amount of funding being transferred to municipalities to help alleviate this infrastructure deficit and reach sustainability goals there was limited prescriptive guidance given to municipalities and monitoring and accountability done by the government.

Within the Office of the Auditor General (2016) report it was found that Infrastructure Canada did not implement any "performance measurement strategy" (pg.3) that could have helped determine if the fund was meeting its objectives, and to effectively report back to Parliament and the Canadian public. This lack of reporting and monitoring is quite important because there were large amounts of money put into this program that was not accounted for. Within the report it states that $\$ 13$ billion was paid out in the first round of the Gas Tax Fund which continue to pay out $\$ 2$ billion each year (pg.3). That is a lot of taxpayer money to be spending on a program where the results are not being adequately reported and synthesized for true measurements of success. Furthermore, the audit found that Infrastructure Canada "did not systematically track or report on the preparation and use of the integrated community sustainability plans, or take other steps to promote them" (pg.5). The lack of monitoring being done aids in the Auditor's conclusion (2016) that even though funding was provided to 
municipalities, Infrastructure Canada could not adequately demonstrate that the fund was helping to improve the sustainability of municipalities and regions.

Contrary to this finding about Infrastructure Canada, the Office of the Auditor General (2016) report did note that the Green Municipal Fund (GMF) created by the Federation of Canadian Municipalities did do a much better job of tracking and measuring how their funding was being spent. Yet, both Infrastructure Canada and FCM failed in providing guidance, or framework for municipalities or regions to follow when creating an ICSP. A study by Ling et al., (2009) states that there are no specific templates created or given throughout the ICSP program that outlines what the plans should contain or how they should be created. Having no source materials to help guide the ICSPs can lead to a lack of prioritization of social equity within ICSPs, especially since the ICSP funding was stated to be used for hard infrastructure projects. The Federation of Canadian Municipalities (FCM) in conjunction with Dr. Amelia Clarke created an implementation guidebook for sustainable community plans for Canadian municipalities, which is one of the only formal guidebooks that provides resources and/or discusses best practices about ICSPs. This guide (FCM \& Clarke, 2012) outlines five 'key successes' for implementation of an ISCP including: oversight, partner engagement, community actions, monitoring and measurement, and communications. They have gathered this information from a review of 27 community sustainability plans across Canada (FCM \& Clarke, 2012). Throughout their guidebook they use examples from three case studies, Whistler, British Columbia; Hamilton, Ontario and Montreal, Quebec to help illustrate their best practices. They do a "plan to plan" (pg.6) comparison of the three different municipal ICSPs, highlighting their advantages and disadvantages. For example, one disadvantage mentioned in reference to the Whistler report is that "only implementing organizations are recognized" (pg.6), meaning within 
Whistler there is only a certain number of organizations that are participating in the sustainability plan and they get told which tasks they will be doing, whereas a disadvantage they found for the Montreal plan is that "partners do not always choose needed actions" (pg.6), because the community partners pick which projects and aspects of the sustainability plan they will be pursuing. Throughout the guidebook they give different examples of success stories from each of the plans for other municipality/regions to learn from. Yet, findings yielded little indication that this background paper was distributed amongst regions and municipalities. In all interviews conducted for this thesis, no municipal/regional participant stated that they had received this guidebook from the FCM, when asked about receiving any guidance or best practice documents. It should also be noted that the guidebook was created in 2012, where the ICSP program started in 2005 , thus the guidance book may have come after a majority of plans were created.

Additionally, when asked, about receiving any sort of best practices or guidance material from either the FCM or the Federal government all municipal or regional interview participants stated that they did not receive any guidance materials. Even though there was the existence of the Prime Minister's External Advisory on Cities and Communities (2005) and that it was very extensive background and implementation document, that also highlights the importance of equity within sustainability planning, it was not mentioned in the interviews as something the participants had seen or used before.

The interview with the GMF/ FCM employee was in line with this observation who stated that guidebooks were something that still needed to be developed, and that there was a lack of material on the best practices for things like community engagement and integrating equity within the ICSPs. This ambiguity of direction for the ICSPs, and lack of guidance from the FCM and different levels of government likely played a large role in the inadequate attention 
given towards equity principals in ICSPs. If social equity is not highlighted within a framework or emphasized it makes sense that it does not become a priority.

Moreover, in the interview with the GMF/ FCM employee they stated that ICSP applications went through a very thorough process of review in order to receive funding, noting that the plans needed to address the triple bottom line approach to sustainability. When asked whether the GMF funded social sustainability or social equity projects they stated that there was, "flexibility within the funding application to put a stronger focus on the social aspect if that was important to the community but it was not something $[\mathrm{FCM}]$ necessarily required or encouraged directly". They acknowledge that social sustainability and public engagement are necessary components of any sustainability plan, yet there was never a significant focus on building social infrastructure or enhancing social/cultural elements. It is here that we see the issue, as understood by many scholars, sustainability when put into practice tends to just prioritize environmental or economic dimensions over social, equity or cultural dimensions unless there is a direct framework or guidance that helps it move beyond these dimensions(Duxbury \& Jeanotte, 2012; Schrock et al., 2015). Yet, we can see that there was very little guidance of framework given to the municipalities and regions to use and follow in creating ICSPs. This problem was also flagged in the original background document in that the Prime Minister's External Advisory on Cities and Communities (2005) stated that some challenges to developing and implementing ICSPs are securing broad, top-level support, creating effective local mechanisms, planning capacity, political change and instability, lack of information and research, and designing effective public participation and implementation processes (2005, Pg.26). It is here, in having a lack of framework or guidance, that we see a gap in information that can lead to the social equity not being given the prioritization it needs. 


\subsubsection{Hard infrastructure vs. soft infrastructure (Social Dimensions of Sustainability)}

In addition to the lack of prescriptive guidance from the federal government, it is also likely that the funding that was distributed to communities from the federal government if they completed an ICSP was somewhat problematic. As mentioned previously, the funding for the ICSPs came from the federal government's Gas Tax Fund, which was to be used to fund projects that would narrow the infrastructure deficit that municipalities across Canada faced (Bradford, 2007; Markvart, 2015). Within Infrastructure Canada's (2008) report on the Gas Tax Fund, it reveals how much money was being transferred from the federal government to the provinces and then municipalities, and what that money was being spent on. The report gives a window into the projects that were completed with those funds. The report outlines that the gas tax fund program money "targets exclusively municipal infrastructure"(pg. 3), and goes farther to say that they GTF "strives to address the diverse needs of communities while contributing to national environmental outcomes of cleaner air, cleaner water, and reduced greenhouse gas emission" (Pg.3). These statements indicate a focus on green infrastructure development. However, the framework that was imposed federally for the ICSP calls for the integration of all five pillars of sustainability including social and cultural dimensions. Sustainability goals involving social and cultural dimensions are not inherently tied to or confined with the green infrastructure goals or changes outlined above. Social sustainability must also involve paying attention to complex socio-economic systems (Grant et al., 2016) in addition to access to green infrastructure. Similarly, cultural sustainability dimensions involve increasing diversity of communities, promoting community identity and cohesion, and promoting art and cultural projects (Prime Minister External advisory on Cities and Communities, 2005). It appears that the restricted 
nature of the Gas Tax Funding only being targeted towards hard infrastructure investments may have undermined opportunities for funding soft infrastructure of social sustainability initiatives. This relationship was highlighted in Bradford (2007) study. In which he states that he does not believe that the revenue transfer from the gas tax fund are the appropriate tool to address social sustainability concerns (Bradford, 2007).

As one of the key informants who was an expert on ICSPs attested "in many ways the sustainability planning bit for many municipalities was just an excuse to get funding”, alluding to the fact that integrated sustainability planning was just a means to an end. The expert researcher went on to explain that of the reason why an integrated, multi-pillar approach was because there was a "recognition of system planning", the idea that you cannot plan new infrastructure or fix old infrastructure anymore without thinking of other system and community impacts, or how infrastructure is intrinsically tied to health, equity, and accessibility. Understanding that the base goals of the ICSPs was to receive money for infrastructure changes helps shine a light on why social equity and/or social sustainability was not a high prioritization or as strong in some of these sustainability plans.

These conclusions and ideas from the expert research go in line with some of the findings done by Grant et al., (2016) in their study. Within their study of ICSP planning in Atlantic Canada, they have a section that looks at the planners' perspectives on sustainability planning, and the majority of planners they interviewed stated negative remarks towards the ICSP process, seeing it as just a check-list they needed to meet to get their funding (Grant et al., 2016). A majority of the remarks made were questioning the ability of the ICSP to actually succeed in creating sustainable cities, especially when the funding was being spent on infrastructure developments like roads, and bridges, and waste management systems (Grant et al., 2016). 
Through the results of this study it can be seen that social equity was not always explicitly addressed or prioritized. One reason for this could be that the funding for these plans did not prioritize social equity or explicitly address it. The focus on green infrastructure projects weakens the ICSP framework because if only infrastructure projects are being funded, little attention needs to be given to social and cultural dimensions of sustainability when creating and implementing the ICSPs. This clash of the two ideas does not help in addressing social equity, for it is apparent that the federal government did not prioritize social equity or social sustainability, but just leaned on the integrated sustainability framework as a means to end.

\subsection{Limitations of Study \& Recommendations for Future Research}

There are a few limitations of this study that are worth exploring in future research. One limitation of the research conducted was the limited sample size of the semi-structured interview participants. In most cases, only one person from each municipality was interviewed, limiting the data for each area. Thus, this sample size cannot be used to draw generalizations or representative conclusions about ICSPs and how they address social equity. Instead this was an exploratory research study that looked to further the understanding of how ICSPs in Ontario addressed social equity and was cautious of conclusive results and generalizations. Having more participants from each area would help in better understanding the process of creating and implementing the sustainability plans. It would give a wider perspective on how social equity was addressed. As well future studies could place further emphasis on the role and significance of plan authorship (i.e. whether it was led by consultant groups, vs. in house municipal staff), and could reflect on how authorship may have shaped the processes of creating and implementing the sustainability plans. 
Additionally, the interviews were only with people involved in the implementation and creation of ICSPs, an FCM employee who worked on ICSP applications, and an expert research consultant. This limits the scope of understanding of how ICSP addressed equity and how variance of community participation influenced addressing social equity, for there were no community members consulted. Especially when looking at social equity, it would be beneficial in future research to include interviews from community members that were in the jurisdiction of the sustainability plans to see if they had the opportunity to participate in the creation, implementation and/or benefits of the plans.

Further, another limit to this study is the ranking system used to describe the results of the document analysis. This ranking system is only one way of describing the analysis, it is part of the story, not the entire results section. The ranking is subjective in that it is not a set score for each theme within the ICSPs, but a way to represent the qualitative findings of each theme. Other methods of summarizing the results could have been used, like tables that classified the plans as "stronger and weaker" etc.

As well, it should be noted that the demographics of a municipality and level of diversity therein is known to impact policy objectives and outputs (Good, 2005). Researchers have studied the relationship between diversity of a municipality and policy objectives and outputs, showing that there is a strong relationship between these two dimensions (Good, 2005). However, an indepth analysis of the potential role of a municipality's demographics on the degree to which social equity was considered within the creation of the ICSPs was not part of the scope of this thesis. For the purpose of showing the diversity differences in each municipality analyzed in this thesis Tables 8-13 give a general breakdown of the populations' different ethnic backgrounds, all information was taken from Statistics Canada website, using their 2016 Census data (Statistics 
Canada, 2016). Future research analysing social equity within sustainability plans should look closer at the relationship between diversity within municipalities and the impacts it may have on addressing social equity within sustainability plans.

Table 8 Markham Ethnic Origin Census Data

The City of Markham

\begin{tabular}{r|r|r|r|} 
Characteristics & Total & Male & \multicolumn{1}{l|}{ Female } \\
\cline { 2 - 4 } & & & \\
\cline { 3 - 4 } Total - Ethnic origin for the population in private & 327400 & 159725 & 167675 \\
households - 25\% sample data & & & \\
\cline { 3 - 4 } North American Aboriginal origins & 1130 & 510 & 625 \\
\cline { 3 - 4 } Other North American origins & 22360 & 11310 & 11045 \\
\cline { 2 - 4 } European origins & 72825 & 35885 & 36945 \\
\cline { 3 - 4 } Caribbean origins & 10665 & 5010 & 5655 \\
\cline { 2 - 4 } Latin; Central and South American origins & 5205 & 2465 & 2750 \\
\cline { 2 - 4 } African origins & 7520 & 3690 & 3830 \\
\cline { 3 - 4 } Asian origins & 242105 & 117750 & 124355 \\
\cline { 3 - 4 } Oceania origins & 230 & 135 & 100 \\
\cline { 3 - 4 } & & &
\end{tabular}

Table 9 York Region Ethnic Origin Census Data

York Region

\begin{tabular}{r|r|r|r|}
\hline Characteristics & Total & Male & Female \\
\cline { 2 - 4 } & & & \\
\cline { 2 - 4 } Total - Ethnic origin for the population in private & 1100950 & 537645 & 563305 \\
households $-25 \%$ sample data & & & \\
\cline { 3 - 4 } North American Aboriginal origins & 9930 & 4820 & 5110 \\
\cline { 3 - 4 } Other North American origins & 130745 & 65260 & 65485 \\
\cline { 3 - 4 } European origins & 523255 & 256655 & 266600 \\
\cline { 3 - 4 } Caribbean origins & 28270 & 13520 & 14750 \\
\cline { 2 - 4 } Latin; Central and South American origins & 24720 & 11910 & 12810 \\
African origins & 27410 & 13730 & 13680 \\
\cline { 3 - 4 } Asian origins & 514515 & 248995 & 265520 \\
\cline { 3 - 4 } Oceania origins & 1040 & 560 & 485 \\
\cline { 3 - 4 } & & &
\end{tabular}


Table 10 Greater Sudbury Ethnic Origin Census Data

The Greater City of Sudbury

\begin{tabular}{r|r|r|r|} 
Characteristics & Total & Male & Female \\
\cline { 2 - 4 } & & & \\
\cline { 3 - 4 } Total - Ethnic origin for the population in private & 161820 & 79490 & 82325 \\
households - 25\% sample data & & & \\
\cline { 3 - 4 } North American Aboriginal origins & 20680 & 10250 & 10430 \\
Other North American origins & 75170 & 36350 & 38815 \\
\cline { 2 - 4 } European origins & 118890 & 58125 & 60765 \\
\cline { 2 - 4 } Caribbean origins & 890 & 425 & 465 \\
\cline { 2 - 4 } Latin; Central and South American origins & 645 & 305 & 345 \\
\cline { 3 - 4 } African origins & 1460 & 700 & 760 \\
\cline { 3 - 4 } Asian origins & 4795 & 2485 & 2310 \\
\cline { 3 - 4 } Oceania origins & 135 & 65 & 70 \\
\cline { 3 - 4 } & & &
\end{tabular}

Table 11 Kingston Ethnic Origins Census Data

The City of Kingston

\begin{tabular}{r|r|r|r|}
\hline Characteristics & Total & Male & Female \\
\cline { 2 - 4 } & & & \\
\cline { 3 - 4 } Total - Ethnic origin for the population in private & 114420 & 54520 & 59905 \\
households $-25 \%$ sample data & & & \\
\cline { 3 - 4 } North American Aboriginal origins & 6545 & 3155 & 3390 \\
\cline { 3 - 4 } Other North American origins & 42125 & 20110 & 22010 \\
\cline { 3 - 4 } European origins & 85075 & 39900 & 45175 \\
\cline { 3 - 4 } Caribbean origins & 1100 & 550 & 555 \\
\cline { 2 - 4 } Latin; Central and South American origins & 1375 & 650 & 720 \\
\cline { 3 - 4 } African origins & 2075 & 1035 & 1040 \\
\cline { 3 - 4 } Asian origins & 9285 & 4640 & 4645 \\
\cline { 3 - 4 } Oceania origins & 265 & 150 & 120 \\
\cline { 3 - 4 }
\end{tabular}


Table 12 Ajax Ethnic Origins Census Data

The Town of Ajax

\begin{tabular}{r|r|r|r|} 
Characteristics & Total & Male & Female \\
\cline { 2 - 4 } & & & \\
\cline { 2 - 4 } Total - Ethnic origin for the population in private & 119180 & 57680 & 61495 \\
households - 25\% sample data & & & \\
\cline { 3 - 4 } North American Aboriginal origins & 2000 & 895 & 1105 \\
\cline { 3 - 4 } Other North American origins & 21860 & 10775 & 11080 \\
\cline { 3 - 4 } European origins & 52870 & 25315 & 27550 \\
\cline { 2 - 4 } Caribbean origins & 18530 & 8710 & 9820 \\
\cline { 2 - 4 } Latin; Central and South American origins & 5425 & 2615 & 2820 \\
African origins & 7135 & 3515 & 3620 \\
\cline { 2 - 4 } Asian origins & 44030 & 21565 & 22465 \\
\cline { 3 - 4 } Oceania origins & 175 & 90 & 80 \\
\cline { 2 - 4 } & & &
\end{tabular}

Table 13 Frontenac County Ethnic Origin Census Data

Frontenac County

\begin{tabular}{r|r|r|r|} 
Characteristics & Total & Male & \multicolumn{1}{l|}{ Female } \\
\cline { 2 - 4 } & & & \\
\cline { 2 - 4 } Total - Ethnic origin for the population in private & 146715 & 70835 & 75885 \\
households - 25\% sample data & & & \\
\cline { 3 - 4 } North American Aboriginal origins & 8425 & 4085 & 4340 \\
\cline { 3 - 4 } Other North American origins & 55825 & 27065 & 28760 \\
\cline { 3 - 4 } European origins & 110300 & 52470 & 57830 \\
\cline { 3 - 4 } Caribbean origins & 1240 & 630 & 605 \\
\cline { 2 - 4 } Latin; Central and South American origins & 1485 & 695 & 785 \\
African origins & 2195 & 1070 & 1125 \\
\cline { 3 - 4 } Asian origins & 9745 & 4875 & 4870 \\
\cline { 3 - 4 } Oceania origins & 300 & 170 & 125 \\
\cline { 3 - 4 } & &
\end{tabular}

Lastly, this thesis is limited in that ICSP program started in 2005, making it a program that is about fifteen years old. Thus, some of the participants within the interviews either did not directly work with creating the sustainability plan themselves, or that they worked on it numerous years ago, and had to rely on notes and documents to be able to answer the interview questions, instead of having a recent recollection of events. 


\section{CONCLUSION}

Sustainability planning has become very prominent in the last thirty years, and there has been a push for planning to be done with an integrated sustainability lens (Portney, 2003; Markvart, 2015). Canada has participated in adopting the sustainability model for planning, working specifically with the 2005 Budget plan that introduced the Integrated Community Sustainability Plans (ICSPs) program. This studies' objectives were to add to the growing research around sustainability planning and equity by looking at six of Ontario's ICSPs. The two research questions that drove this thesis were: 1) How have ICSPs considered equity principles in their design and implementation; and, 2) How do variation in the degree of community involvement in sustainability planning influence how equity is addressed? This study answered these questions through document analysis and informant interviews. The overall consensus was that within the creation of the ICSPs social equity was not explicitly considered. This does not mean there was zero presence of social equity initiatives and goals in the sustainability plans, but that social equity did not have a strong and large presence throughout the ICSPs, even if there were sections dedicated to social equity or social sustainability. In order for social equity to be achieved through a sustainability planning lens there needs to be consistency and accountability. Although, if the plans are emphasizing meaningful action to help close the gap of inequity within a community there must be follow through with implementing the policy. Of course, this is not a phenomenon that only effects social equity and sustainability planning (Talen, 1996; Brody \& Highfield, 2005; Loh, 2012); the importance of social equity should not be undermined by a lack of implementation.

The results of this research uncovered and explained some reasons for why and how social equity was not explicitly considered throughout the ICSPs. One explanation was a 
disconnect between policy goals and details of implementation. This lack of implementation accounts for the barriers in considering social equity within sustainability planning, specifically in regard to the ICSP studies. Through the semi-structured, interviews more information was learned about the actual implementation and process of the plans, leading to a few of these findings. For example, The Town of Ajax, whose sustainability plan was ranked fairly high among themes like accessibility, community focused initiative's etc. (Table $2 \& 4$ ) did not have employees working in their sustainability office at the time of the study, which implies a lack of capacity in Ajax to actually implement their sustainability plan.

Another result that explains weak consideration of social equity was the lack of prescription and guidance from the FCM and federal government. While there were many documents created by the FCM and federal government, when interviewing participants none of them could recall receiving any guidance or best-practices to follow. Furthermore, the actual prescribed framework of the ICSPs was extremely vague, and without enforcing focus on social equity and social sustainability these dimensions fall through the cracks. In practice, sustainability tends to prioritize environmental or economic dimensions (Duxbury \& Jeanotte, 2012; Schrock et al., 2015). Along with the lack of prescriptive guidance form the federal government, the actual funding agreement that distributed money to the municipalities was convoluted. The dichotomy between the gas tax fund being used to alleviate municipal infrastructure debt and the funding going to "green infrastructure projects" (Infrastructure Canada, 2008), while needing an integrated sustainability plan weakens the ability to consider and prioritize social equity.

Even though this study helps in highlighting the gaps in considering social equity within ICSPs in Ontario, in the instances in which social equity was addressed, a majority of ICSPs 
examined in this study excelled at themes of procedural equity, specifically public engagement. This study discussed that this may be due to public engagement being one of the only guidelines given by the federal government in creating an ICSP (Infrastructure Canada, 2008), and because public engagement is understood as essential in order to be successful in sustainability planning (Portney, 2003; Pearsall \& Pierce, 2010; Markvart, 2015; Schrock 2015). Yet strong public engagement is not enough for eradicating social inequity through sustainability planning. There needs to be as equally strong a presence in distributional equity goals as there is in procedural equity goals (Pearsall \& Pierce, 2010; Teelucksingh \& Masuda, 2014). That was not seen in this study. These findings add to the discourse on social equity in sustainability planning and open up opportunities for further research.

One key area for further research is a more explicit look at social equity and The City of Kingston's sustainability governance model. Within the scope of this study, Kingston's community led sustainability corporation was not seen to make any larger of an impact on considering social equity, compared to the other government led ICSPs. If at all, there was deviation from the original ICSP which could lead to a dismissal of the social equity and social sustainability initiatives originally created in the plan. Further research should be done on Kingston's Sustainability Corporation and how it engages with the public, the types of events and goals it pursues, and a more in-depth analysis on the effect of community-lead sustainability planning, all of which were beyond the breadth of this study. In addition, more research should be done that involves the actual community members that were affected and impacted by the ICSPs, to learn their perspective and figure out if/what of their needs is missing, communitybased research would be very beneficial for advancing this research. As well, research should look further into the actual implementation of the plans; this could be done through more 
interviews within each municipality/regions office to see gather a better understanding of the implementation strategies and outcomes.

This study highlighted the gaps in considering social equity within six Ontario ICSPs, but that does mean all the plans had poor outcomes. There were a few plans that really stood out in demonstrating that they understood the importance of addressing social equity and social sustainability. The City of Markham is a great example of an ICSP that had put in meaningful effort in many areas of procedural and distributional equity. Their ICSPs high rankings in many of the different themes aids in understanding social equity, even ten years ago, is and can be considered in sustainability planning at a municipality level. From the interviews, many of the participants stated that if they were to re-make the ICSPs today there would be an increased understanding of the importance of social equity, community participation and involvement of marginalized community members. They believe that this would be reflected in sustainability plans today. It is this admission, and the growing research on social equity more broadly, that gives hope to future endeavours in sustainability planning. 
Appendix A: Sample Questions of Semi Structured Interview Guide

\title{
Examining considerations of social sustainability and equity within Integrated Community Sustainability Plans in Ontario
}

\author{
Semi-structured Interview Guide \\ Sabrina Güvenç
}

\section{Perhaps we can start with some background on how your municipality/region has gone about creating and implementing the ICSP}

How does your region/municipality define sustainability for the formation of these plans?

Who was part of the creation of the ICSP?

Who were the key players and organizations?

To what degree did the federal government prescribe what needed to be included within these plans? In what ways?

Was there an overarching theme over area of focus within your sustainability plan?

What were some of the Important projects your municipality/region wanted to work on and why?

What knowledge or information did you draw upon to make these decisions?

Were there any important issues not considered that in hindsight should have received more attention?

Could you please comment on how your communities sustainability planning has evolved since the creation of your ICSP? Do you have the resources to implement your plan? Generally speaking, what are the biggest successes or areas of progress to date?

What are the biggest limitations or areas in need of improvement to date?

\section{We will now discuss community participation within your municipalities/regions ICSP}

How was the public involved in shaping the creation and implementation of the sustainability plan? 
How did your organization notify communities/individuals about the ICSPs and the ability to participate?

Can you talk about which demographics or interests participated the most?

Who might have been excluded or under-represented?

How are certain areas/ populations/communities picked for specific sustainable infrastructure projects?

Does your community receive any support or guidance from other levels of government or the Federation of Canadian municipalities with respect to public engagement strategies?

\section{We will now move onto questions about Equity}

Were equity principles prioritized in the planning process?

How would you define equity in relation to sustainability planning? Would your organization share the same understanding?

How did you or your organization go about ensuring these principles were considered?

If equity was not prioritized was this a conscious decision? Can you explain?

Was there any guidance available or best practices to draw upon to inform your attempt to commit to equity principles? Who provided this? Was this a requirement of the federal government to receive funding for the ICSPs?

How do you measure success or progress related to strengthening equity considerations within the context of ICSPs?

Do you think the ways in which governance and decision-making are carried out impacts the ability to promote equity principles? What do you find to be most effective or ineffective? Were there any barriers to implementing equity principles within your sustainability plan? How can the interests of marginalized groups be protected in sustainability planning? 
Appendix B: Table of All Interview Participants

\begin{tabular}{|l|l|l|}
\hline Employment position & Municipality/Region & Date of Interview \\
\hline Sustainability Manager & City of Markham & $07 / 18 / 2019$ \\
\hline Director of Planning and Development & Frontenac County & $07 / 31 / 2019$ \\
\hline Environmental Director & City of Kingston & $06 / 26 / 2019$ \\
\hline Community Engagement Coordinator & $\begin{array}{l}\text { Sustainable Kingston } \\
\text { Corp. }\end{array}$ & $07 / 03 / 2019$ \\
\hline Coordinator of Earth Care Sudbury & $\begin{array}{l}\text { Greater City of } \\
\text { Sudbury }\end{array}$ & $05 / 30 / 2019$ \\
\hline Professional Planner & York Region & $10 / 17 / 2019$ \\
\hline GMF Employee at FCM & N/A & $06 / 11 / 19$ \\
\hline Expert Research Consultant & N/A & $05 / 14 / 2019$ \\
\hline
\end{tabular}




\section{Works Cited}

Appleton, J. V. (1995). Analysing qualitative interview data: addressing issues of validity and reliability. Journal of Advanced Nursing, 22, 993-997

Austin, A. (2011). Policy reconciliation methodology to create and integrated community sustainability plan (ICSP) for Canadian municipalities. Royal Roads University,1-77

AMO (2007). Integrated Community Sustainability Plan Backgrounder. 1-3

Arnstein, S.R. (1969). A ladder of participation. Journal of American Planning Association, 35(4), 216-224

Berkes, F., Folke, C. (1998). Linking social and ecological systems. Cambridge University Press.

Bos, J. J., Brown, R. R. (2013) Assessing organisational capacity for transitional programs. Technological Forecasting \& Social Change 86, 188-206

Boshmann, E. \& Kwan, M. (2008). Toward Socially Sustainable Urban Transportation: Progress and Potentials. International Journal of Sustainable Transportation, 2:138-157

Bradford, Neil (2007). Placing Social Policy? Reflections on Canada's New Deal for Cities and Communities. Online. PDF

Brody, S. D., and W. E. Highfield. (2005). Does planning work? Testing the implementation of local environmental planning in Florida. Journal of the American Planning Association 71 (2): 159-75.

Campbell, S.D. (2013). Sustainable Development and Social Justice: conflicting urgencies and the search for common ground in urban and regional planning. Michigan Journal of Sustainability, 1, 76-91.

Chapple, K., (2015). Planning sustainable cities and regions: Towards more equitable development. New York, NY: Routledge.

Coburn, D. (2004). Beyond the income inequality hypothesis: class, neo-liberalism, and health inequalities. Social Science \& Medicine, 58(1), 41-56.

Collins, P., Alger, M., Whitelaw, G., Williams, B. (2017). Implementing integrated community sustainability planning: a comparative case study of three mid-sized municipalities in Ontario, Canada. International Journal of Sustainable Development, 20(1/2),124-145.

Coffey, A. (2014). The SAGE Handbook of Qualitative Data Analysis: Edited By Uwe Flick. Sage Publications. 
Community. (2020). In Meriam Webster.com. Retrieved. February $26^{\text {th }} 2020$, From https://www.merriam-webster.com/dictionary/community

Crabtree, B. F., \& \& Miller, W., L. (1999). Doing qualitative research. Sage Publications.

Duxubry, N., Jeannotte S., M. (2012). Including culture in sustainability: an assessment of Canada's Integrated Community Sustainability plans. International Journal of Urban Sustainable Development, 4(1), 1-19.

EarthCare Sudbury. (2010). Earth Care Sudbury Action Plan: Becoming a sustainable community. Online. PDF

Frontenac County. (2009). Sustainable Actions: County of Frontenac Sustainability Project Recommendations. Online. PDF

Good, K., (2005) Patterns of politics in Canada's immigrant-receiving cities and suburbs: How immigrant settlement patterns shape the municipal role in multiculturism policy. Policy Studies. 26. 261-289

Government of Canada. (2005). Agreement Signed on The New Deal for Cities and Communities: New Release. Retrieved from:https://www.canada.ca/en/news/archive/2005/04/agreement-signed-new-deal-cities$\underline{\text { communities.html }}$

Government of Ontario. (2019) List of Ontario Municipalities. Published August $29^{\text {th }} 2019$. Online. URL https://www.ontario.ca/page/list-ontario-municipalities

Gale, N. K., Heath, G., Cameron, E., Rashid, S., \& Redwood, S. (2013). Using the framework method for the analysis of qualitative data in multi-disciplinary health research. BMC Medical Research Methodology, 13(1), 117.

Grant, J. L., Beed, T., \& Manuel, P. M. (2016). Integrated community sustainability planning in Atlantic Canada: Green washing an infrastructure agenda. Journal of Planning Education and Research, 38(1).

Head, B. W. (2007). Community engagement: Participation on whose terms? Australian Journal of Political Science, 42(3). 441-454.

Heynen, N., Perkins, A., H., Parama, R.(2006). The political ecology of uneven green space: the impact of political economy on race and ethnicity in producing environmental inequality in Milwaukee. Urban Affairs Review, 42(1). 3-25.

Infrastructure Canada, Research and Analysis Division (2006) The path towards sustainability. Online. PDF 
Infrastructure Canada. (2008). Gas Tax Fund: Results for Canadians. Retrieved From: http://www.infrastructure.gc.ca/plan/gtf-fte/gtf-fte-03-eng.html

Infrastructure Canada, The Natural Step. (2011). Bridging the Gap in Community Sustainability Planning Implementation and Infrastructure. Online. PDF

Jordan, A. (2008). The governance of sustainable development: Taking stock and looking forwards. Environment and Planning C: Government and Policy, 26(1). 17-33.

Kallio, H., Pietilä, A. M., Johnson, M. \& Kangasniemi M. (2016). Systematic methodological review: developing a framework for a qualitative semi-structured interview guide. Journal of Advanced Nursing, 72 (12). 2954-2965.

Kingston. (2010). Sustainable Kingston Plan. Online. PDF.

Ling, C., Hanna, K., \& Dale, A. (2009). A template for integrated community sustainability planning. Environmental Management, 44(2). 228-242.

Loh, C. (2012). Four potential disconnects in the community planning process. Journal of Planning Education and Research, 32(1), 33-47.

Marbeck Resource Consultants. (2009). Sustainable Community Planning in Canada: Status and Best Practices- Made for the FCM. Online. PDF

Markham. (2011). Markham’s Greenprint Sustainability Plan. Online. PDF

Markvart, T. (2015). Planning for social change towards sustainability investigating local government strategic sustainability planning in Canada. University of Waterloo, 1-301

McClintock, N. (2014). Radical, reformist, and garden-variety neoliberal: coming to terms with urban agriculture's contradictions. Local Environment, 19(2). 147-171.

Minkler, M., Vasquez, V.B., Tajik, M., Petersen, D. (2008). Promoting environmental justice through community-based participatory research: The role of community and partnership capacity. Health Education \& Behaviour, 35(1): 119-137.

Neptis. (2013). Implementing the Growth Plan For the Greater Golden Horseshoe: has the strategic regional vision been compromised? Online. PDF.

Office of the Auditor General of Canada (2016) Report 1- Federal Support of Municipal Infrastructure. Website. http://www.oagbvg.gc.ca/internet/English/parl_cesd_201605_01_e_41380.html 
Owens, K.A. \& Legere, S. (2015). What do we say when we talk about sustainability? , International Journal of Sustainability in Higher Education, 16 (3). 367 - 384

Parker, J., \& Crabtree S. A. (2018). Social work with disadvantaged and marginalised people. Sage Publications Ltd.

Pearsall, H., \& Pierce, J. (2010). Urban sustainability and environmental justice: Evaluating the linkages in public planning/policy discourse. Local Environment, 15(6). 569-580.

Portney, K. E. (2003). Taking sustainable cities seriously: Economic development, the environment, and quality of life in American cities. MIT Press.

Prime Minister's External Advisory on Cities and Communities (2005) Integrated Community Sustainability Planning - A Background Paper. Online. PDF

Rivera, M. A., \& Ward, J. A. (2008). Employment equity and institutional commitments to diversity: Disciplinary perspectives from public administration and public affairs education. Journal of Public Affairs Education, 14(1), 9-20.

Robinson, P., Dale, A. (2012). Urban sustainability: reconnecting space and place. Edited By: Ann Dale, William T. Dushenko, Pamela Robinson. University of Toronto Press.

Roseland, M. (2012). Towards a Sustainable Communities: Solutions for citizens and their governments. New Society Publishers.

Schrock, G., Bassett, M. E., Green, J. (2015) Pursing equity and justice in a changing climate: assessing equity in local climate and sustainability plans in U.S Cities. Planning Education and Research, 35(3). 282-295.

Scholsberg, David. (2007) Defining environmental justice: Theories Movements and Nature. Oxford University Press.

Schlosberg, D., \& Collins, L. B. (2014) From environmental to climate justice: Climate change and the discourse of environmental justice. Wiley Interdisciplinary Reviews: Climate Change, 5(3), 359-374

Statistics Canada (2015). Census metropolitan area (CMA) and census agglomeration (CA). Online: https://www12.statcan.gc.ca/census-recensement/2011/ref/dict/geo009-eng.cfm

Talen, E. (1996). Do plans get implemented? A review of evaluation in planning. Journal of Planning Literature 10: 248-59. 
Teelucksingh, C. \& Masuda, J. (2014). Urban environmental justice through the camera: understanding the politics of space and the right to the city. Local Environment, 19(3). 300-317.

The Natural Step (2018). Integrated Community Sustainability Planning (ICSP): The Process. Online: :http://www.naturalstep.ca/integrated-community-sustainability-planning

Town of Ajax. (2013). Ajax- A Journey to Sustainability: ICSP. Online. PDF

Trainor, A., \& Graue, E. (2013). Reviewing qualitative research in the social sciences. Routledge.

University of Alberta. (2018). Canadian Sustainability Plan Inventory. Retrieved From: https://www.ualberta.ca/augustana/research/centres/acsrc/projects/priorityareas/planning/completed-projects/cspi

Warner, K. (2002). Linking Local Sustainability Initiatives with Environmental Justice. Local Environment, 7(1). 35-47

Wolch, J. R., Byrne, J., \& Newell, J. P. (2014). Urban green space, public health, and environmental justice: The challenge of making cities 'just green enough. Landscape and Urban Planning, 125. 234-244.

World Commission On Environment and Development. (1987). Report of the World Commission on Environment and Development: Our Common Future.

York Region. (2007). York Region Sustainability Strategy: Towards a Sustainable Region. Online. PDF 